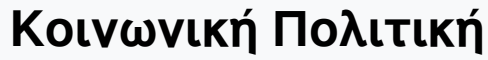

Tóp. 8 (2017)

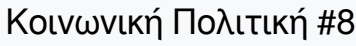

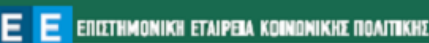 \\ Kn

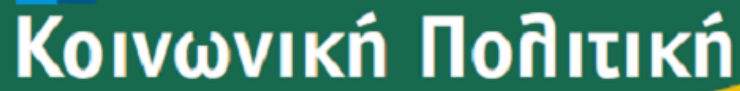

\section{Social Policy}

\section{A $\theta \rho a$ / Articles:}

Stefanos Papanastasiou - Christos Papatheodorou Intergenerational occupational persistence across the worlds of welfare in the EU

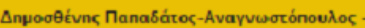

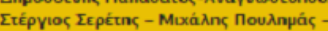
Aגésnç Mnévos

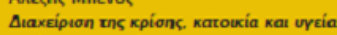

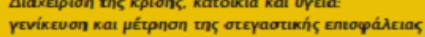

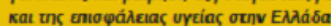

Bayrểnnç Koupapıavór

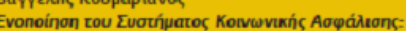

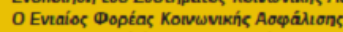

ws oppavewrikó óxnpa yia tmu véa apxitekrovikń

twv ouvtáłєevv

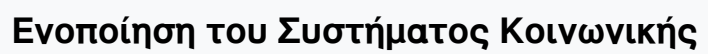

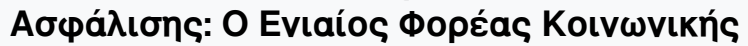

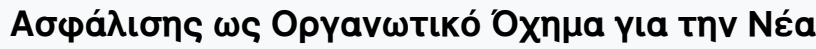

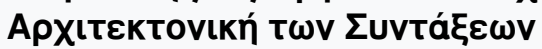

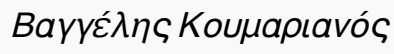

doi: $10.12681 / \mathrm{sp} .14604$

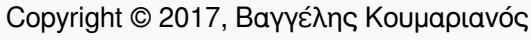

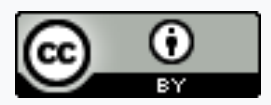

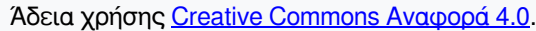

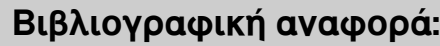

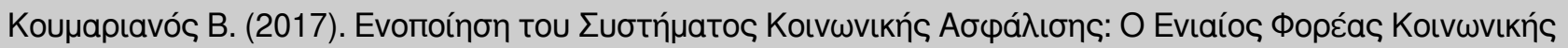

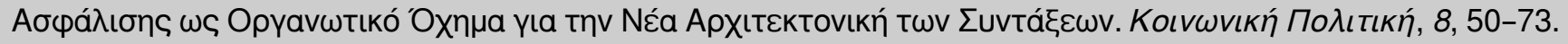
https://doi.org/10.12681/sp.14604 


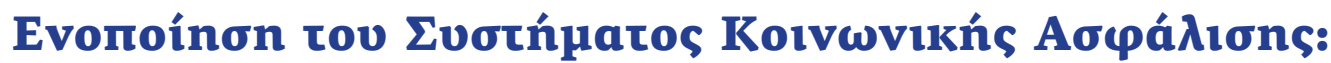

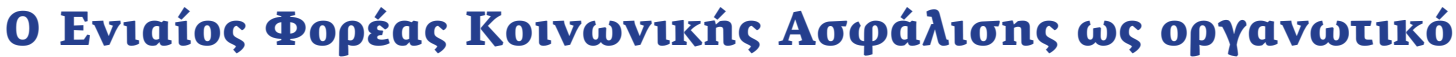

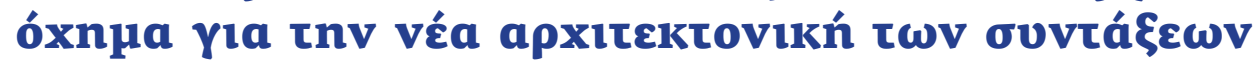

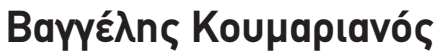

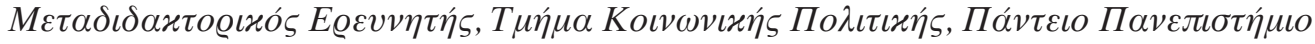

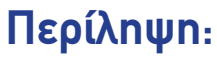

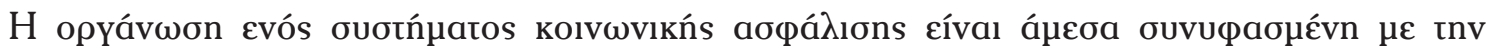

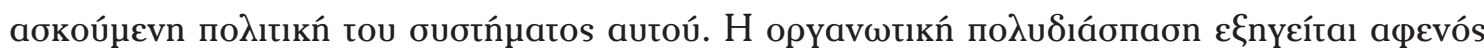

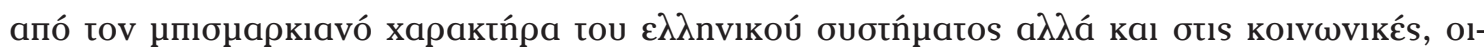

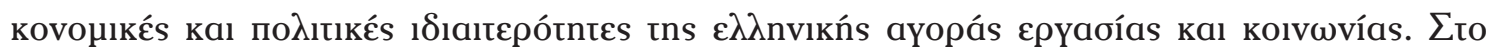

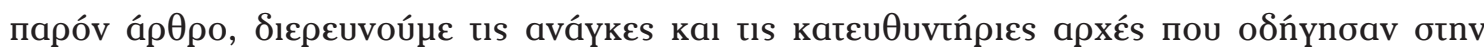

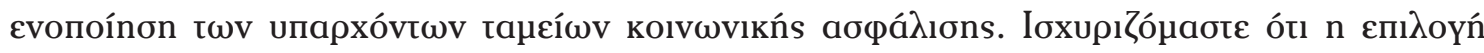

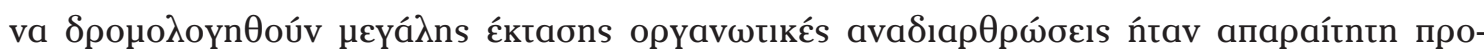

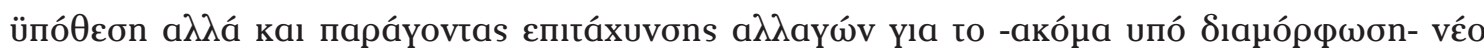

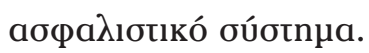

\section{Abstract:}

The organization of a social insurance system is directly connected to the policies delivered by this system. The organizational fragmentation is explained on the one hand by the bismarckian caracteristics of the greek social security system, on the other hand by the social, economic and political particularities of the greek society and labour market. In the present article, we examine the prerequisites and the guiding principles that led to the unification/merge of existing social insurance funds. We claim that the choice to implement organizational restructuring of great extent was a necessary condition and accelerating factor of change for the new social insurance, which is still under devellopment. 


\section{Eıoaywүń}

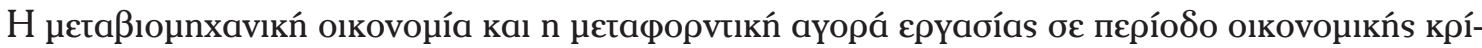

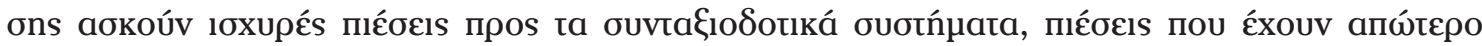

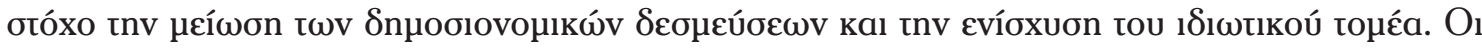

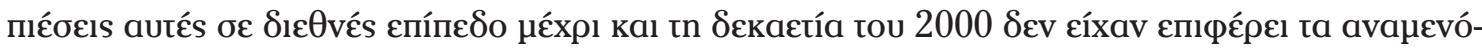

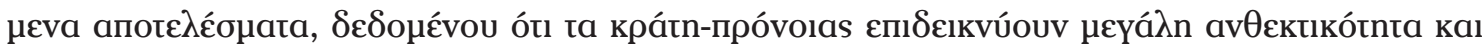

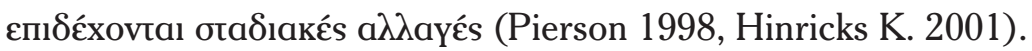

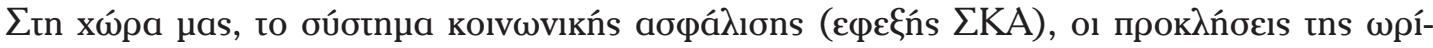

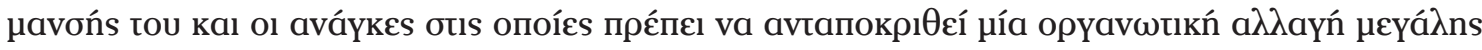

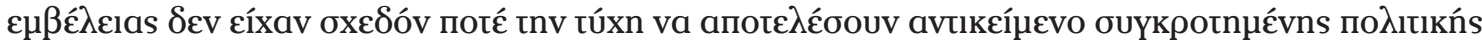

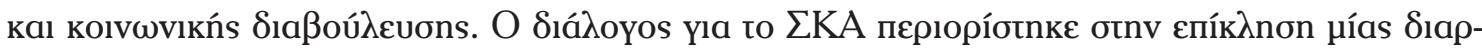

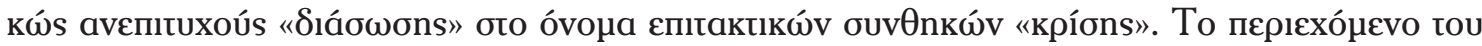

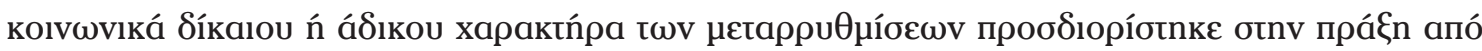

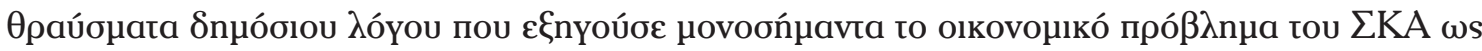

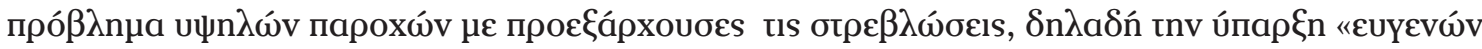

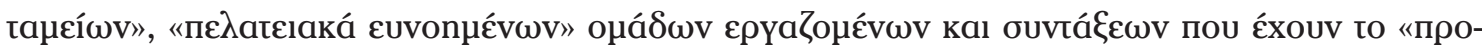

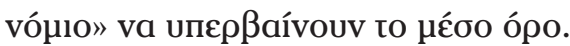

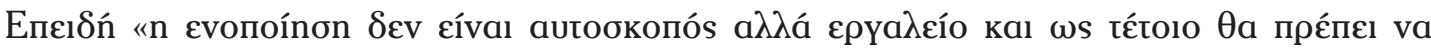

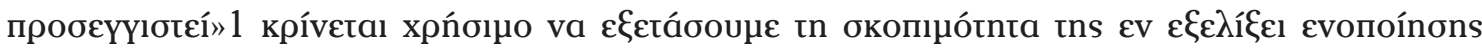

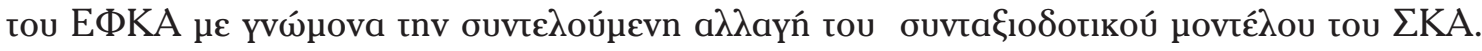

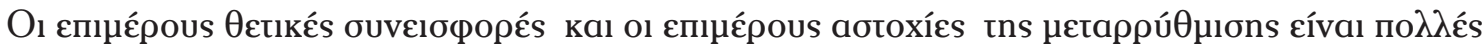

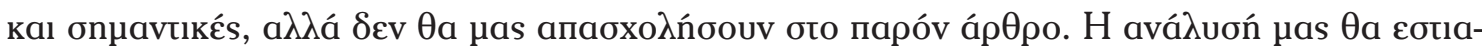

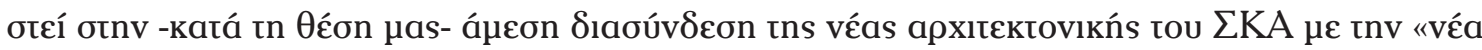

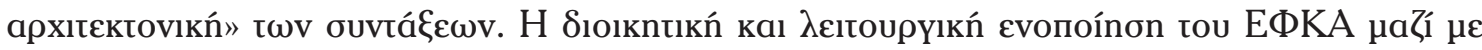

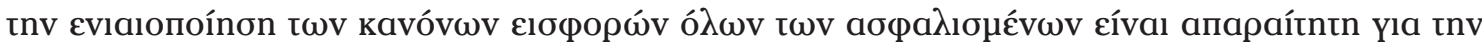

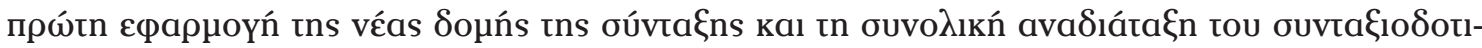
кои́ топі́о一.

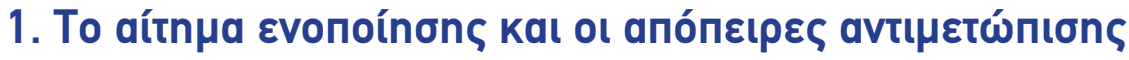

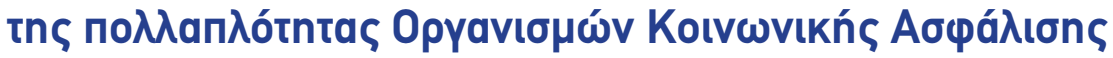

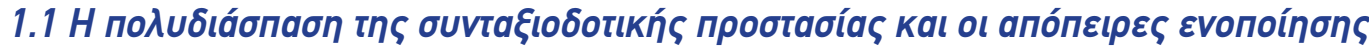

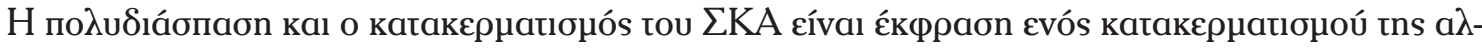

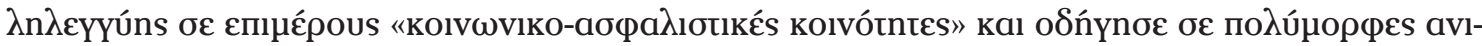

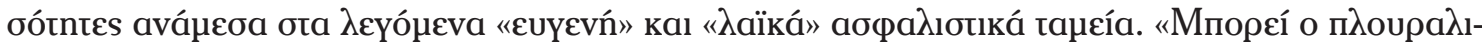

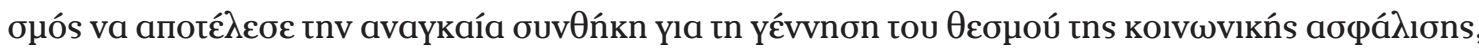




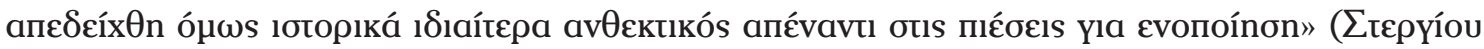

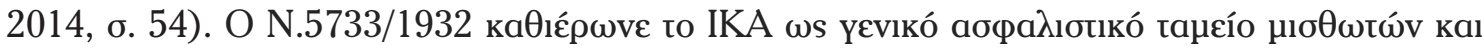

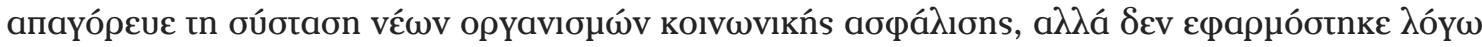

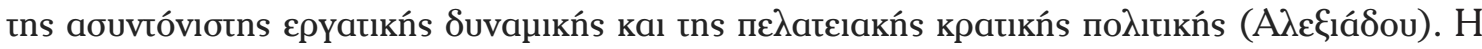

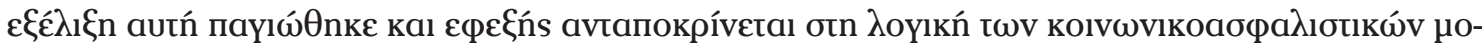

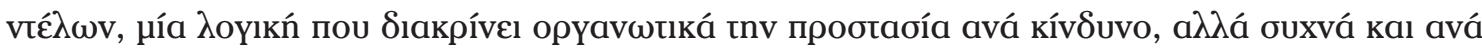

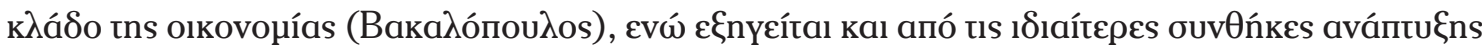

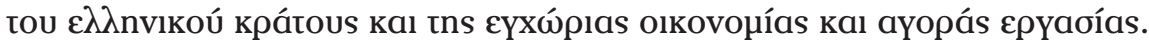

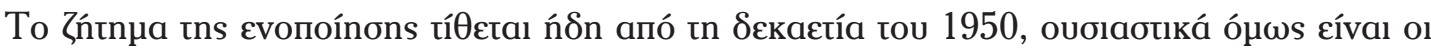

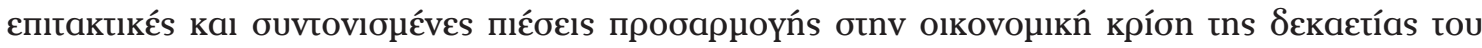

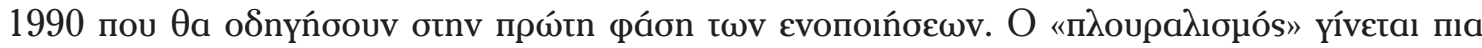

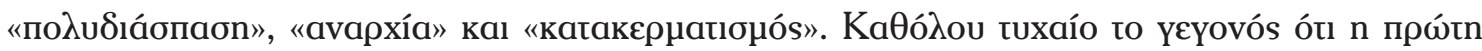

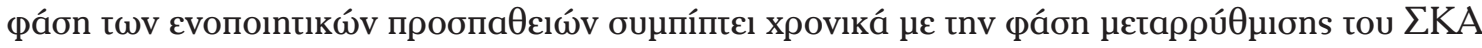

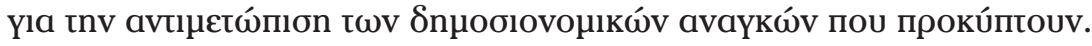

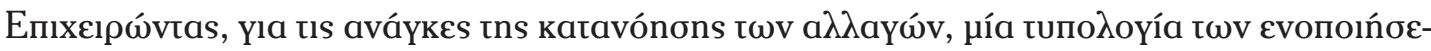

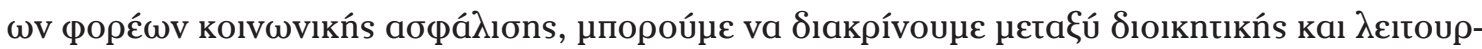

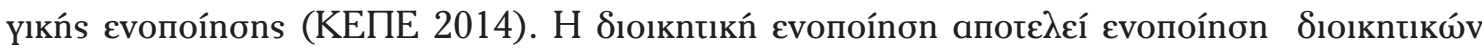

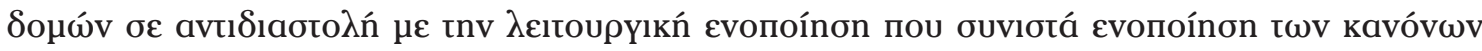

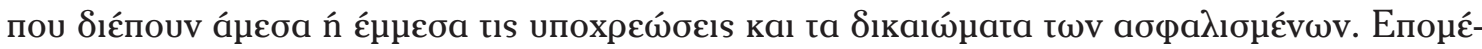

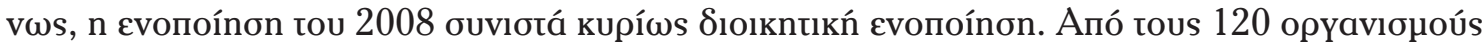

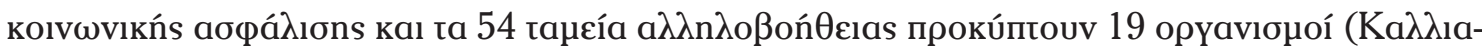

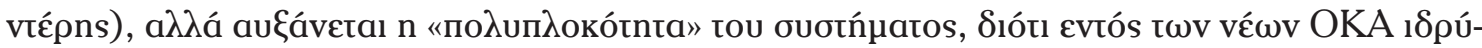

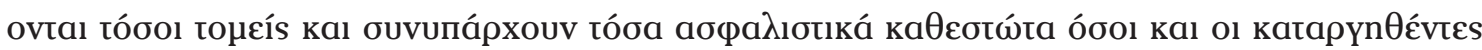
OKA.

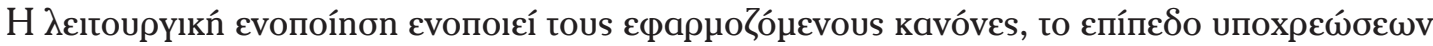

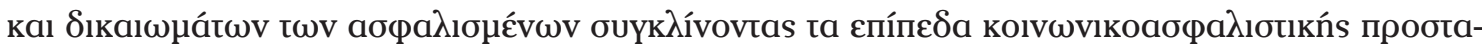

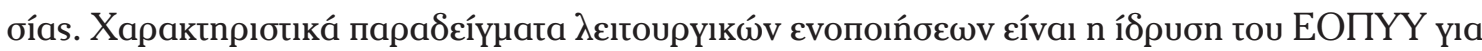

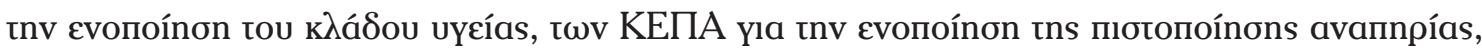

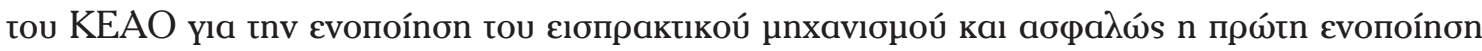

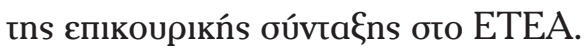

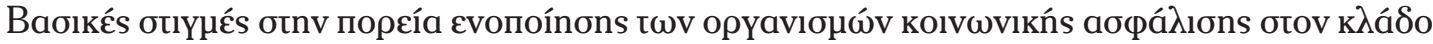

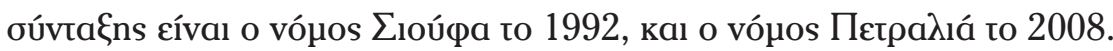

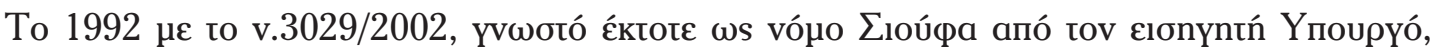

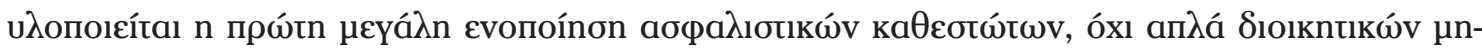

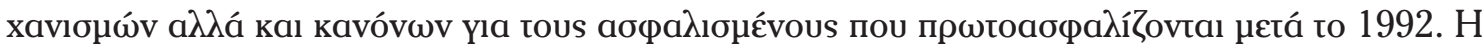

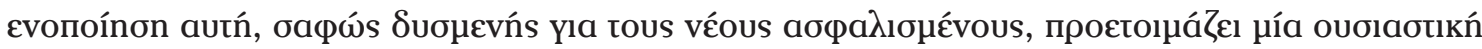

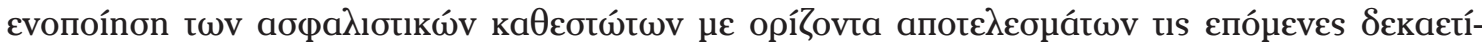

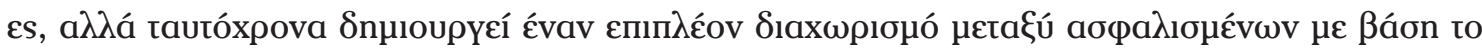

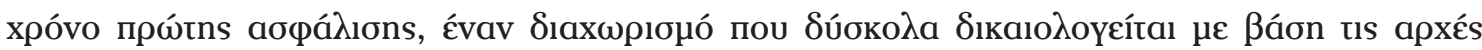

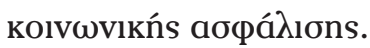

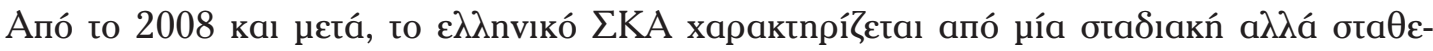

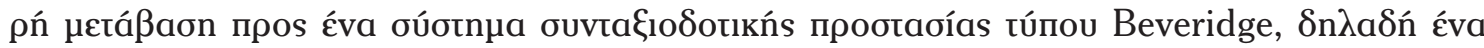




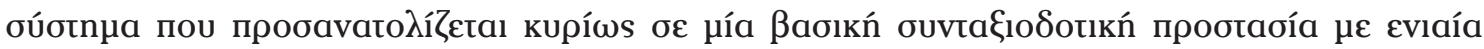

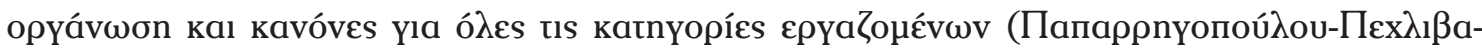

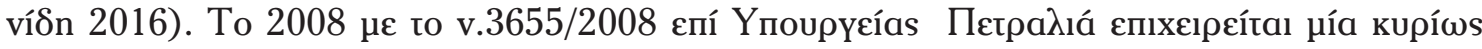

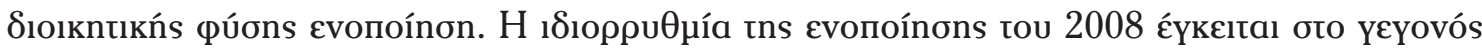

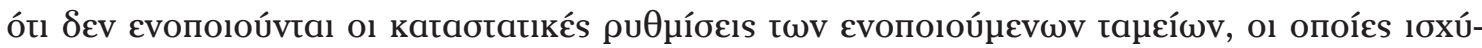
ouv пара́ $\lambda \lambda n \lambda a$.

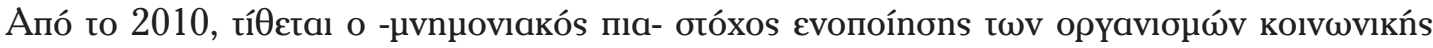

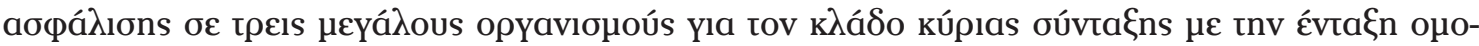

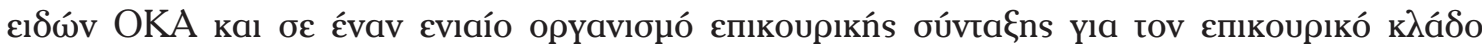
(v.3845/2010).

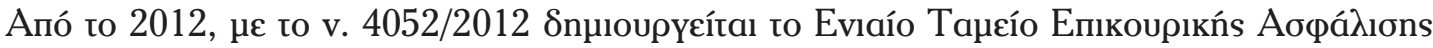

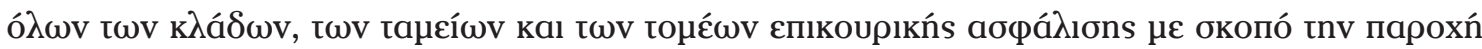

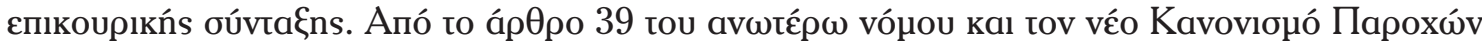

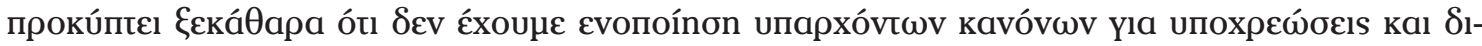

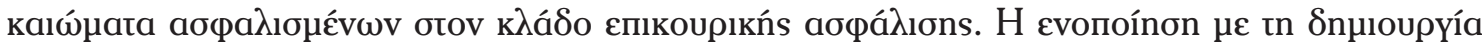

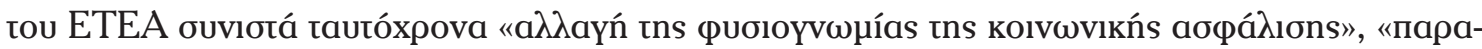

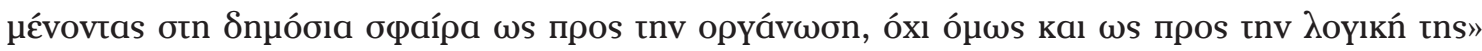

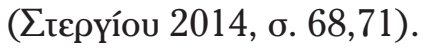

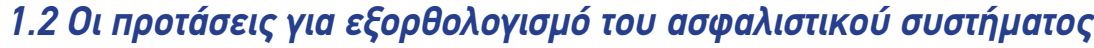

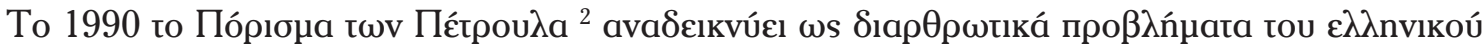

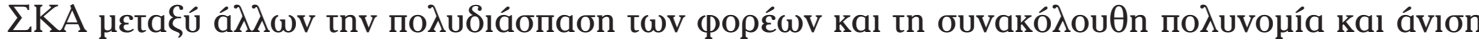

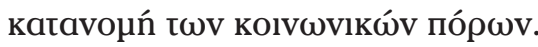

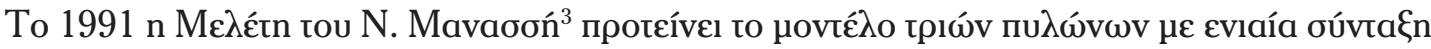

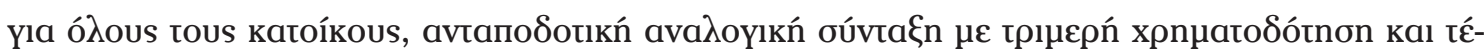

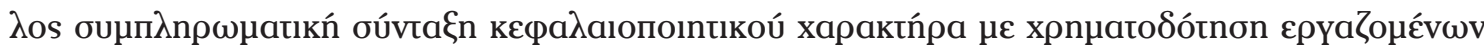
каı єрүоботб́v.

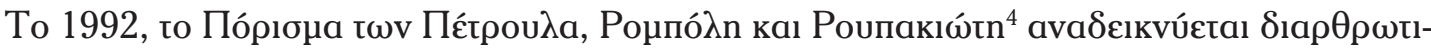

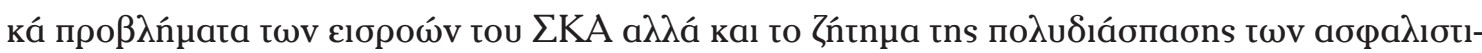

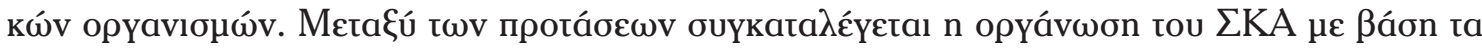

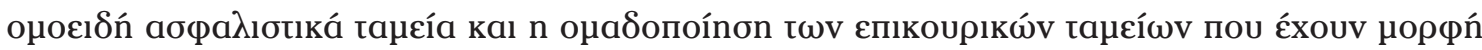
$\mathrm{N} \Pi \Delta \Delta$.

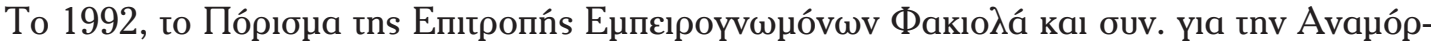

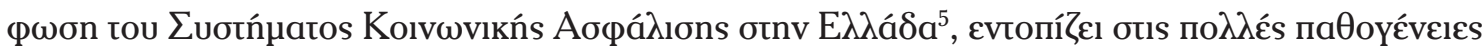

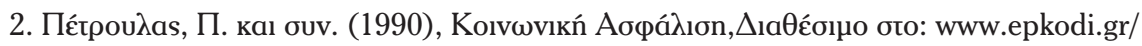

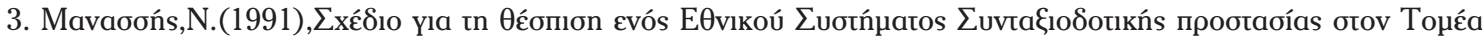

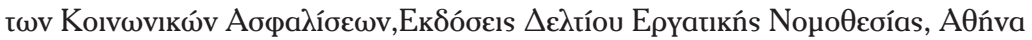

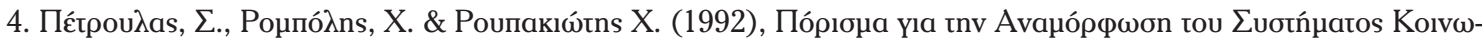

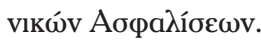

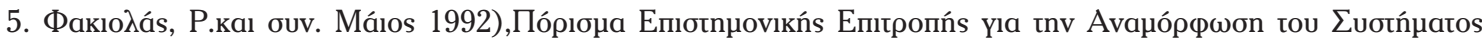

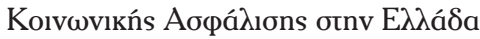




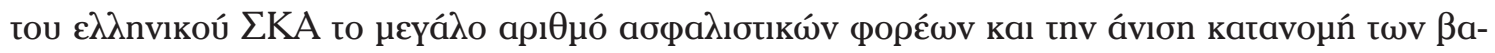

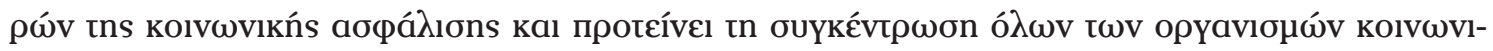

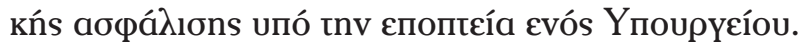

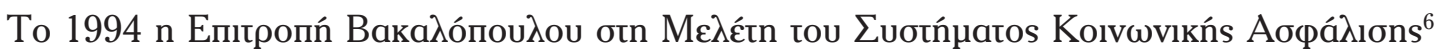

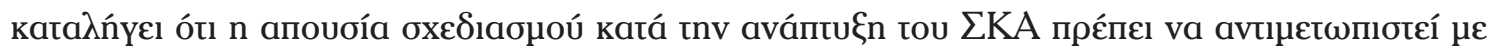

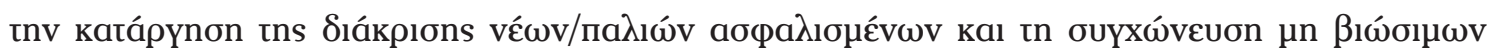

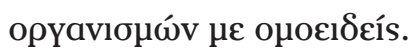

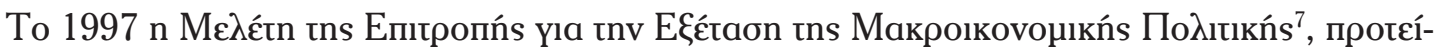

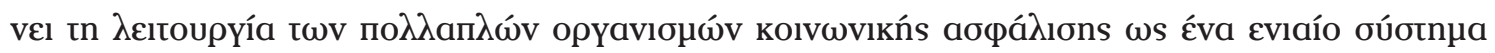

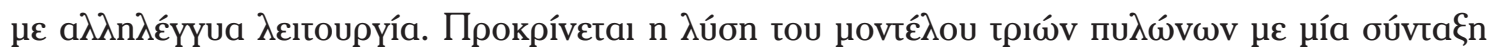

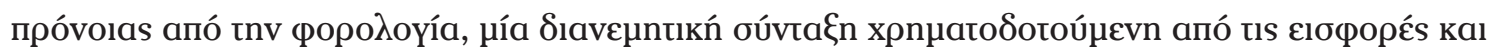

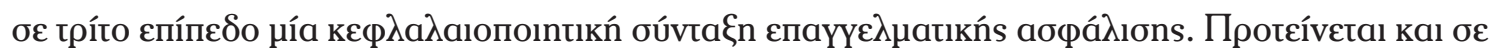

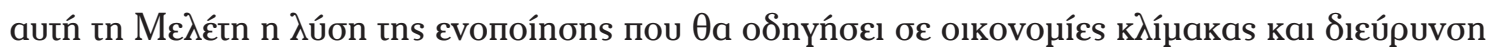

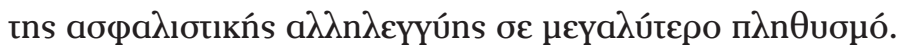

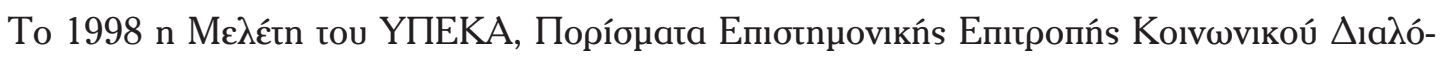

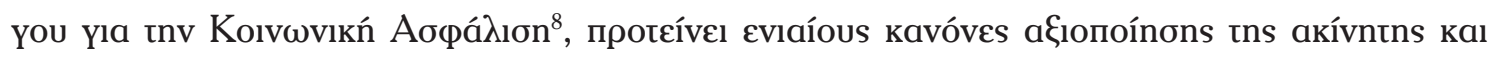

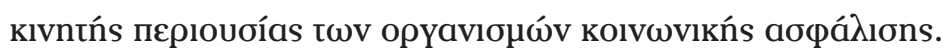

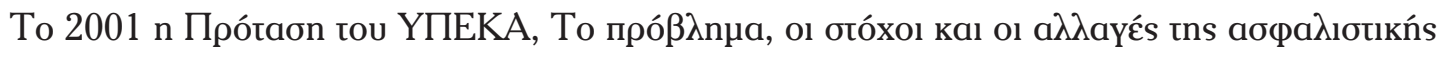

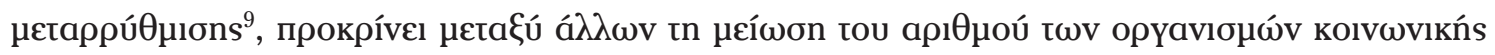

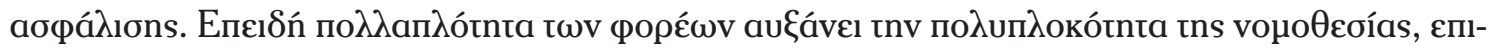

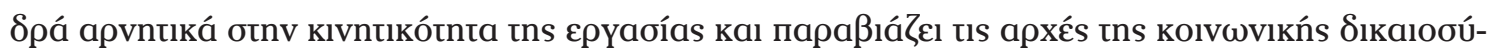

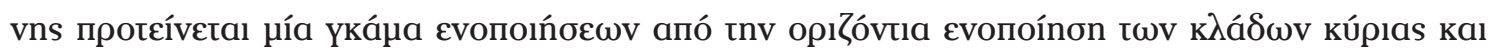

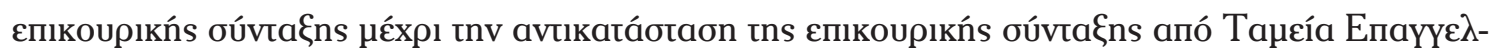

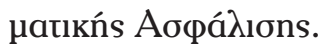

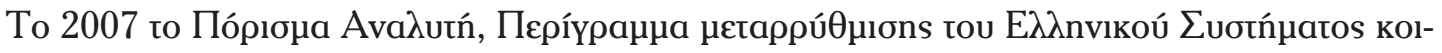

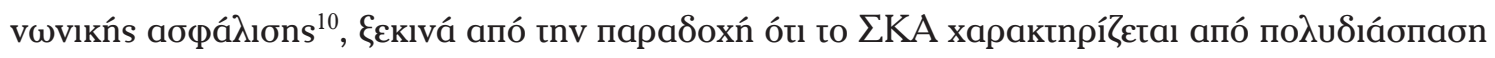

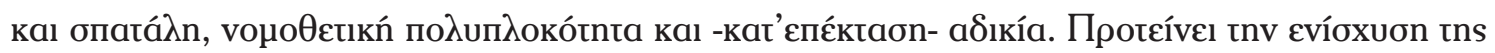

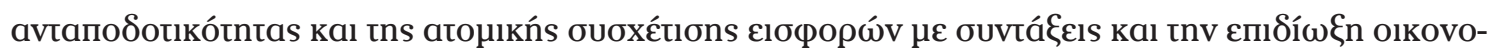

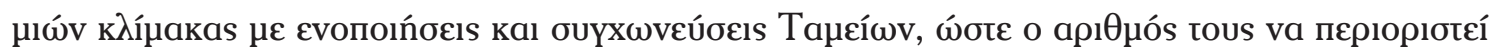

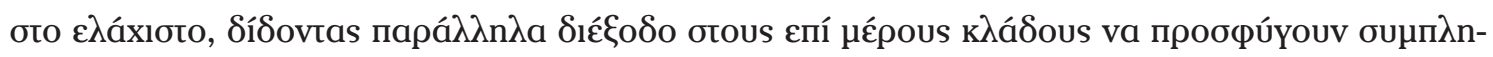

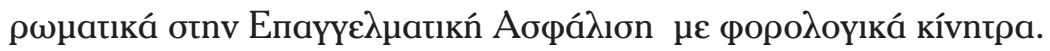

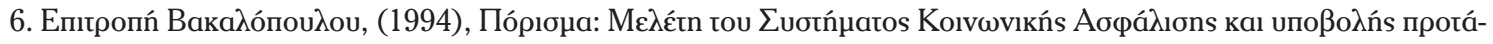

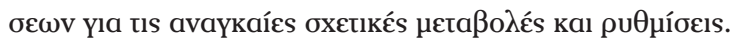

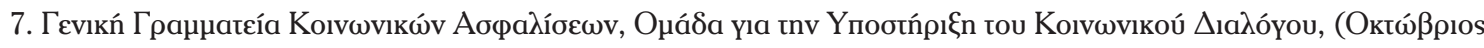

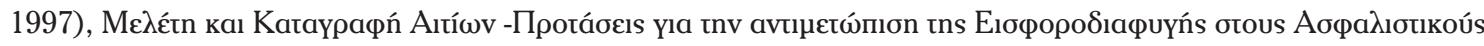
Opyavıouoús Kúpıas Aбфádıons

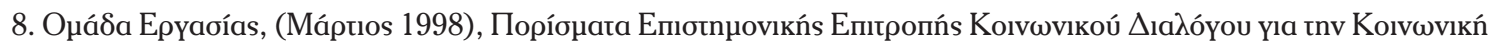
Aбфádıon.

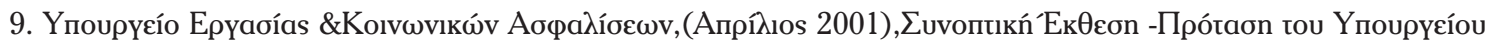

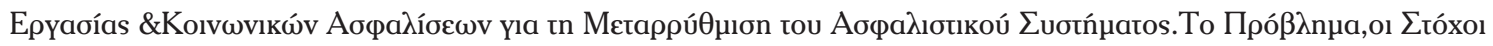

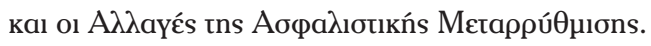

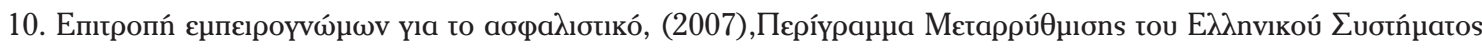

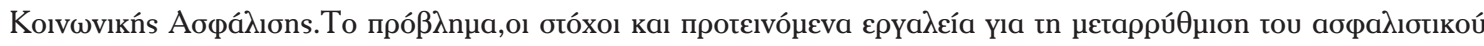
ouotńuatos. 


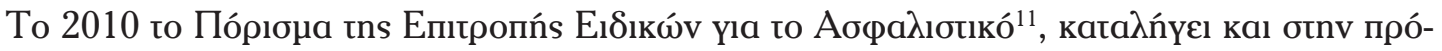

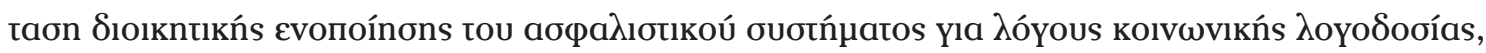

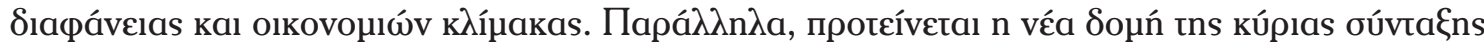

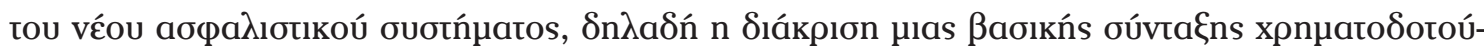

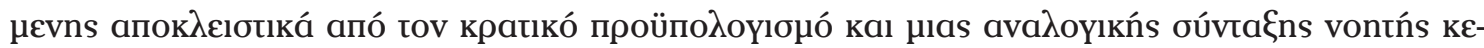

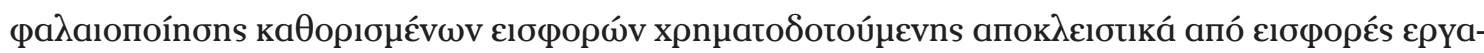

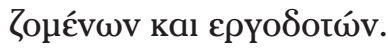

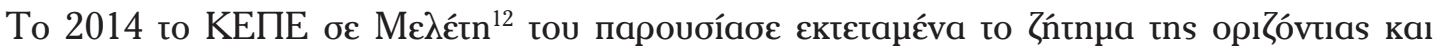

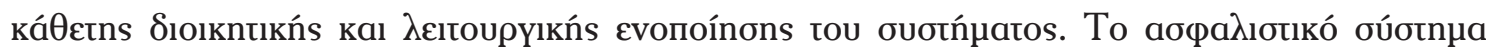

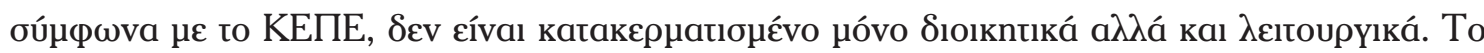

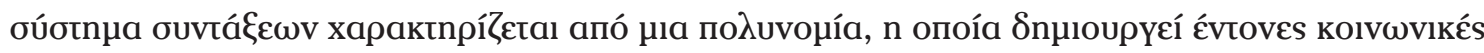

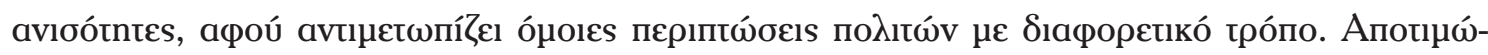

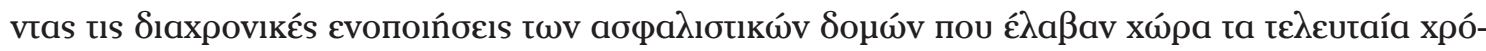

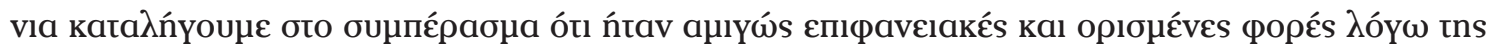

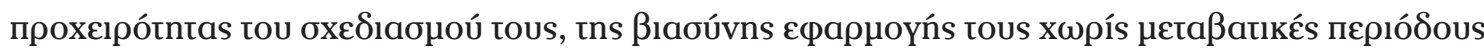

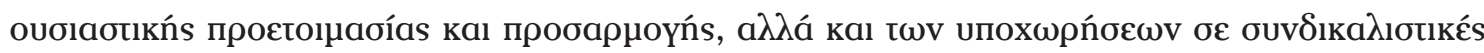

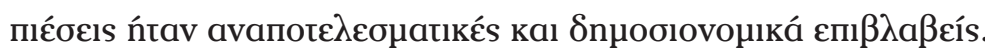

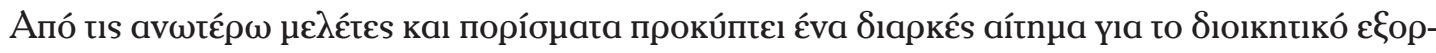

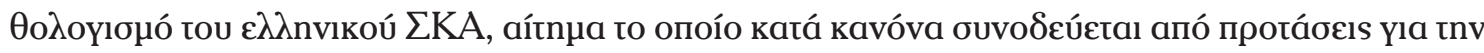

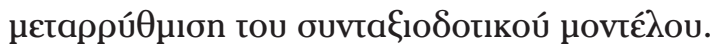

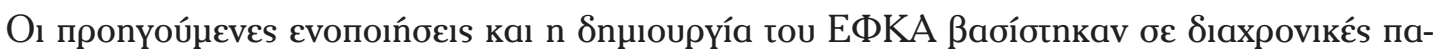

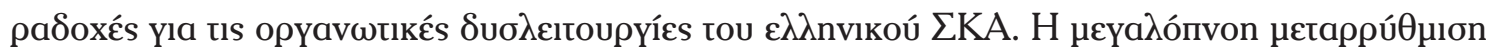

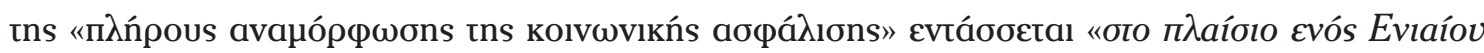

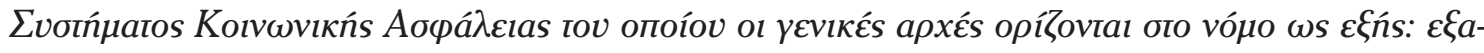

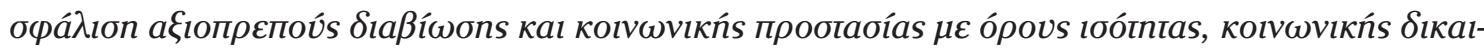

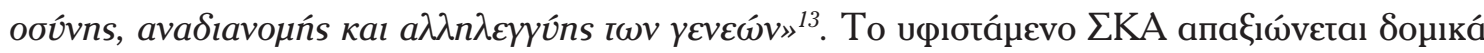

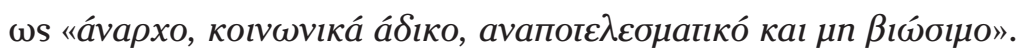

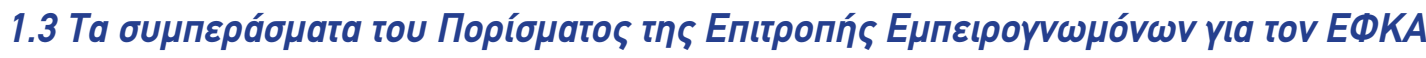

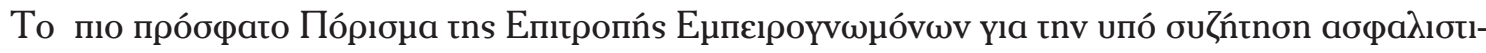

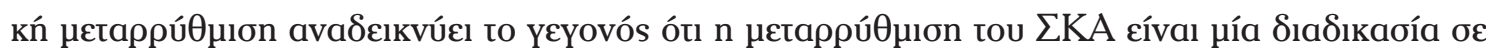

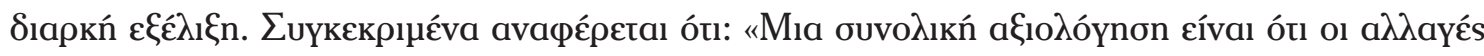

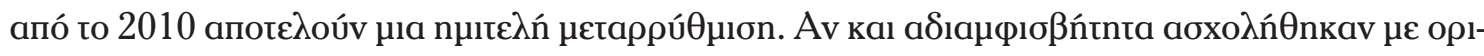

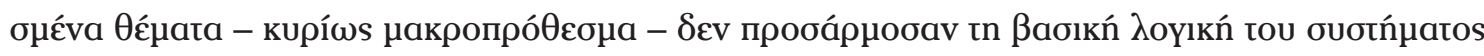
бта véa $\delta \varepsilon \delta o \mu \varepsilon ́ v a »$.

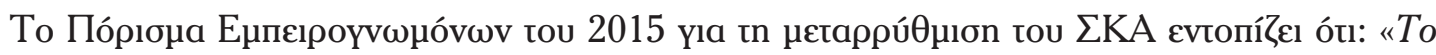

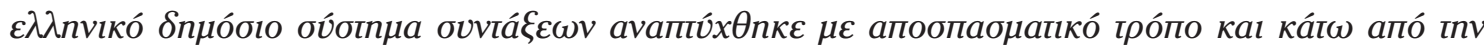

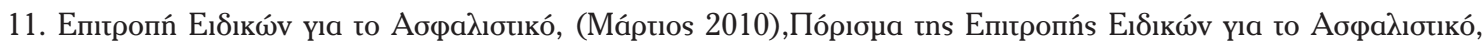

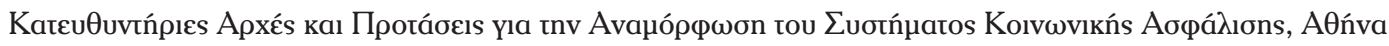

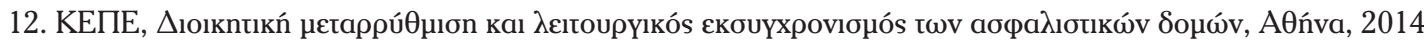

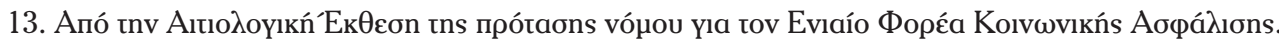




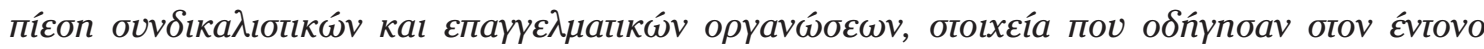

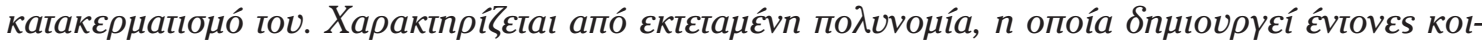

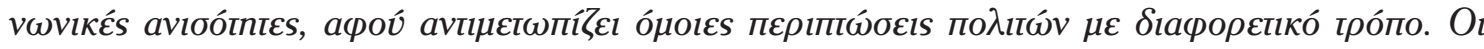

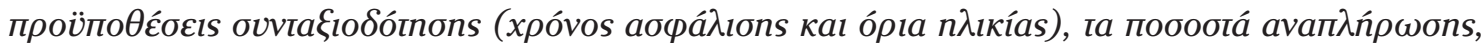

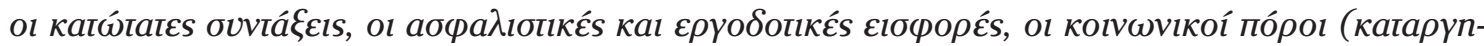

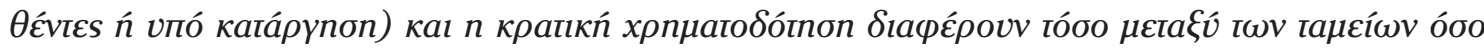
каı $\mu \varepsilon т а \xi \dot{~ a \sigma \varphi а \lambda ı ~}$

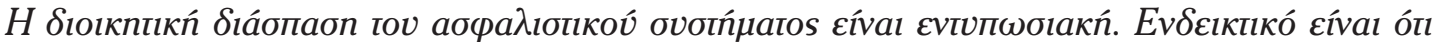

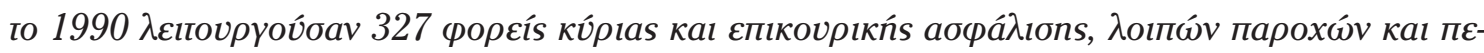

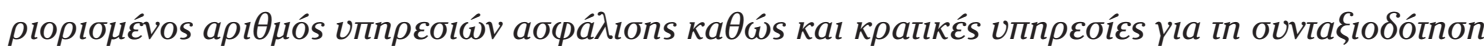

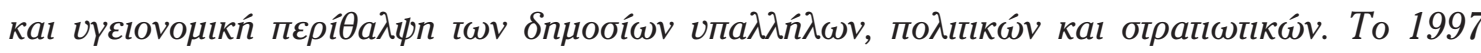

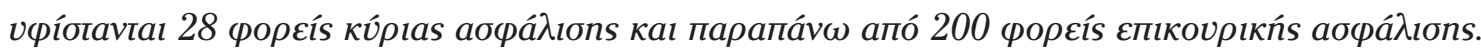

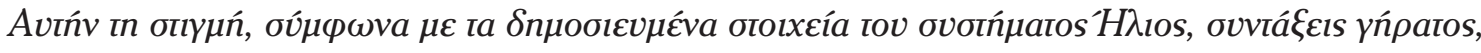

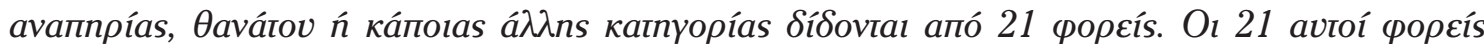

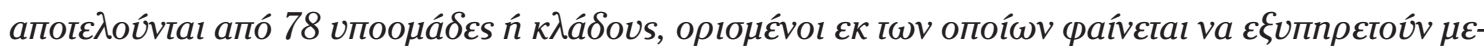

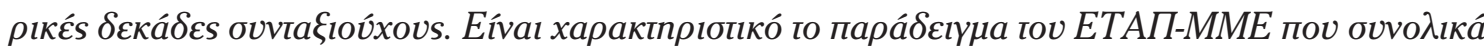

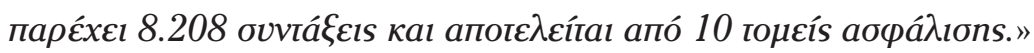

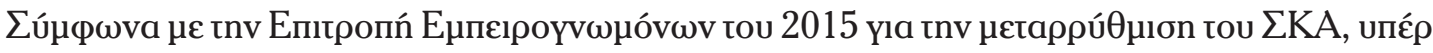

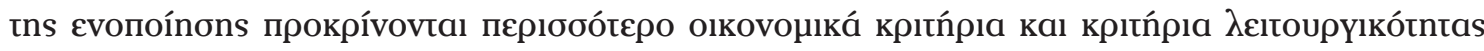

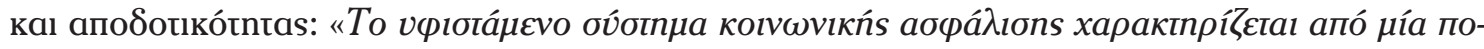

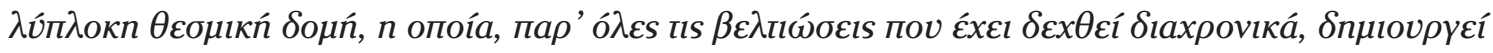

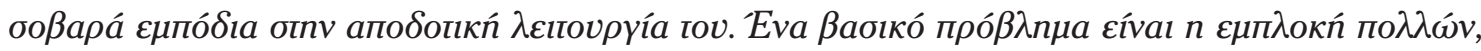

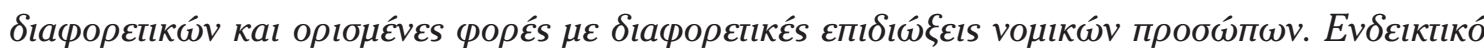

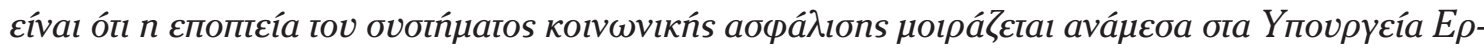

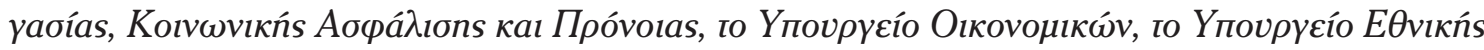

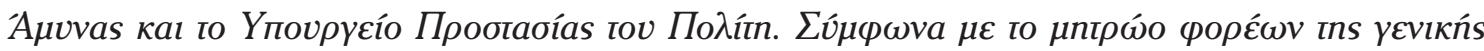

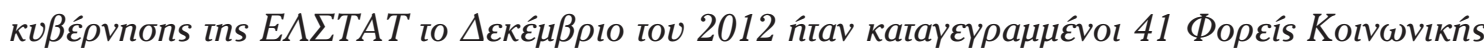

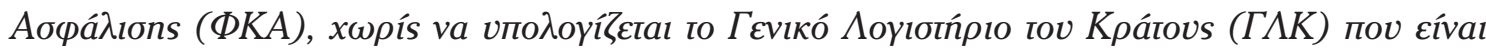

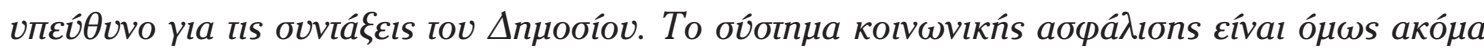

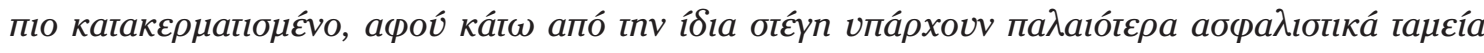

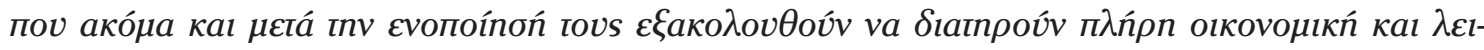

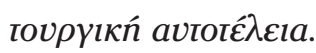

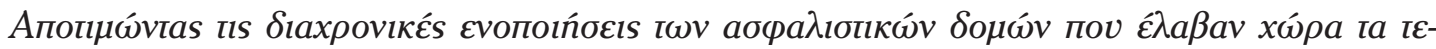

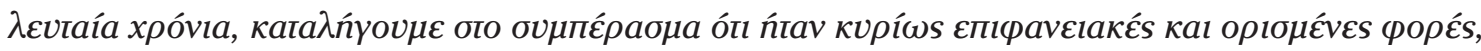

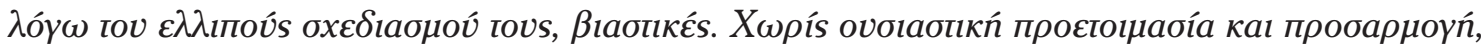

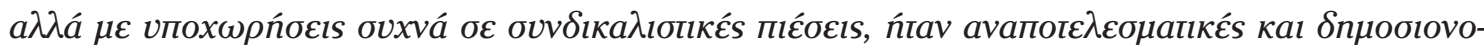

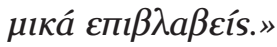

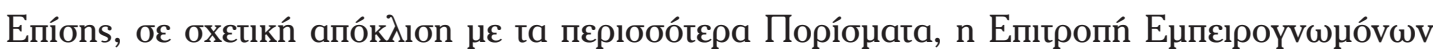

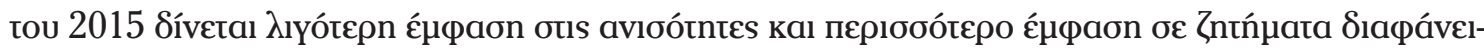

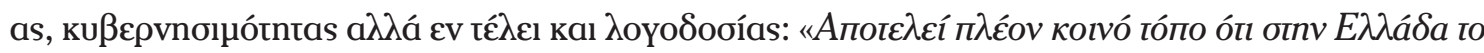

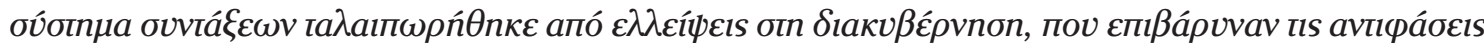

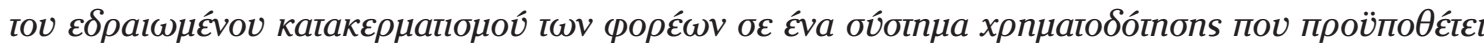




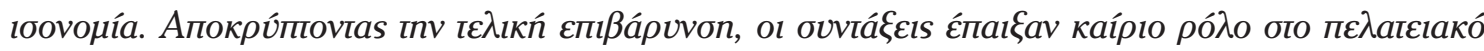

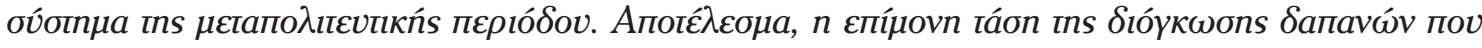

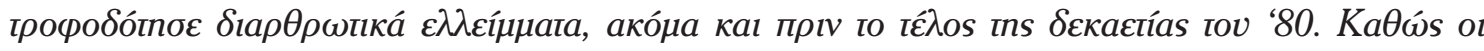

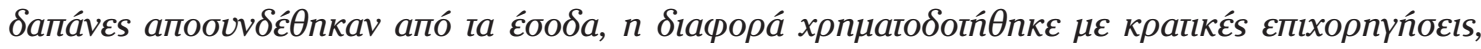

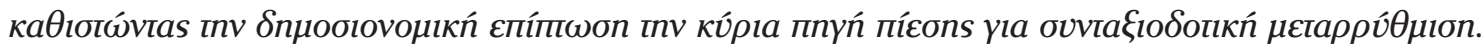

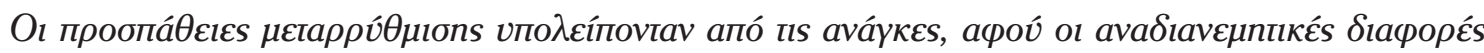

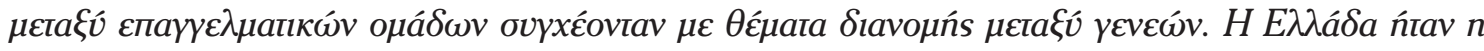

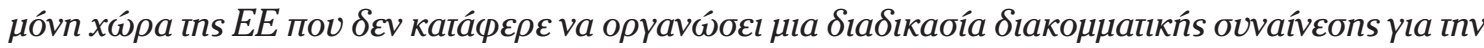

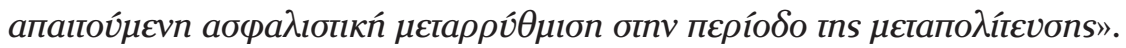

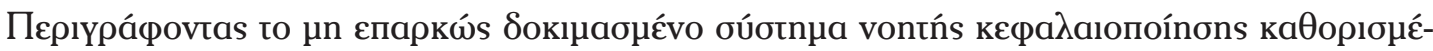

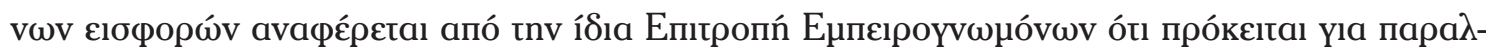

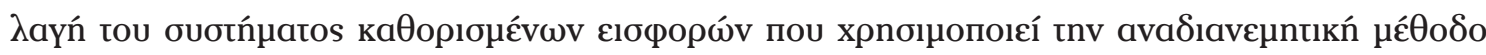

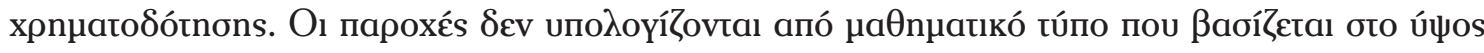

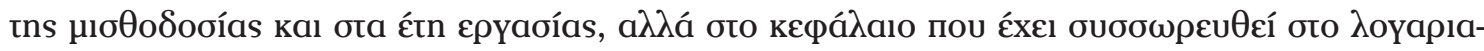

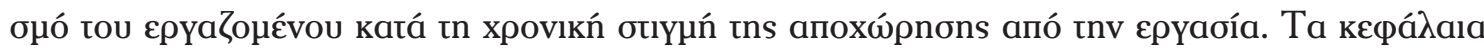

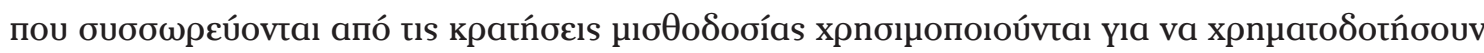

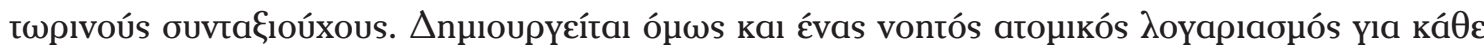

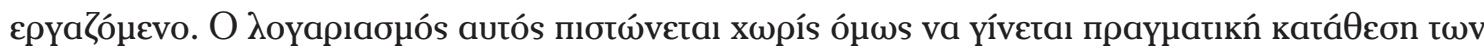

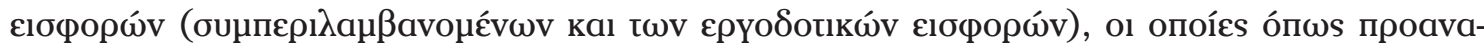

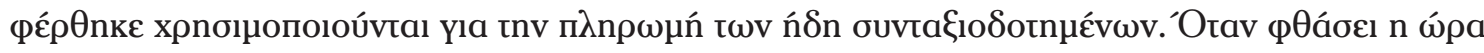

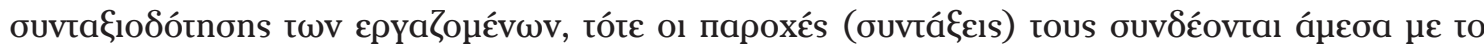

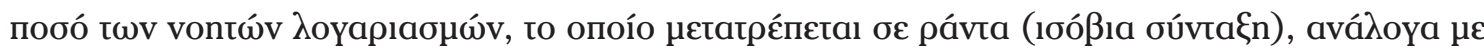

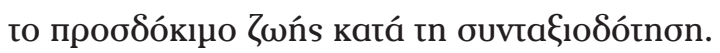

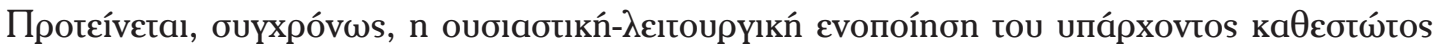

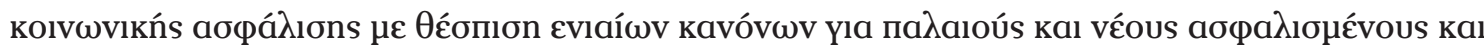

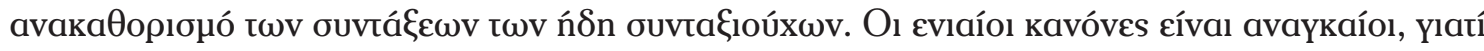

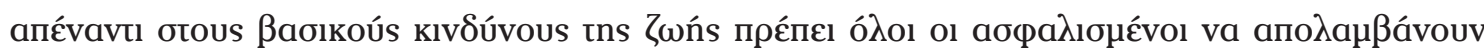

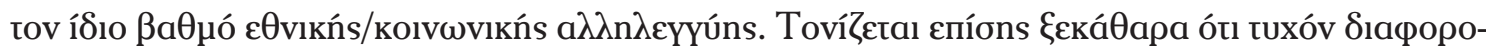

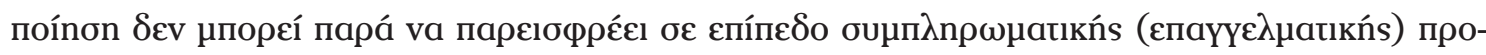

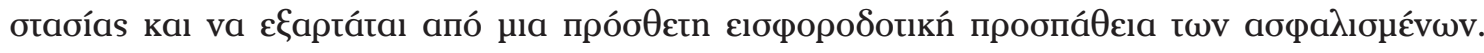

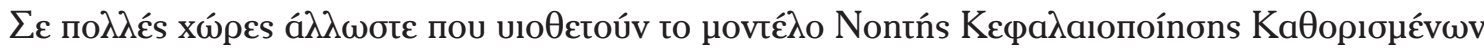

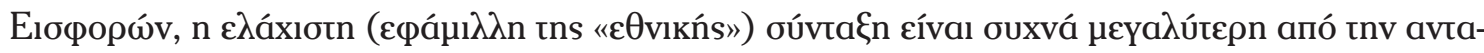

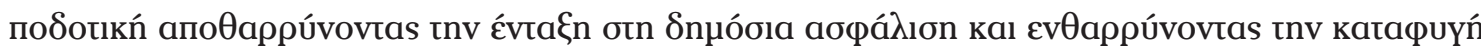

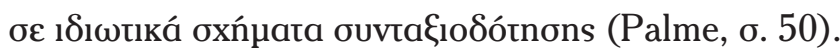

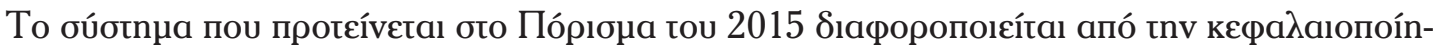

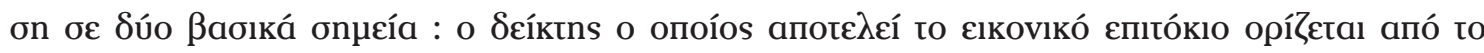

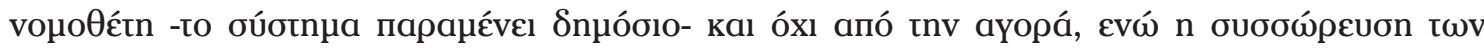

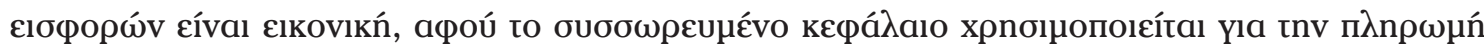

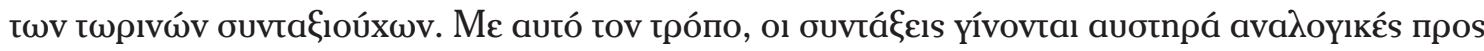

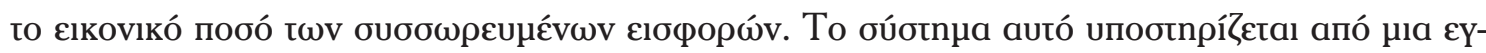

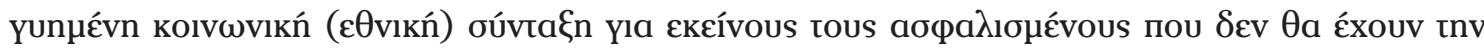

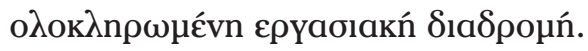




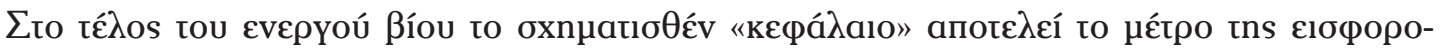

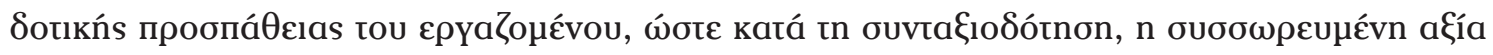

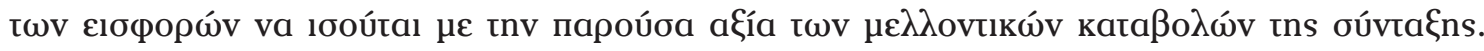

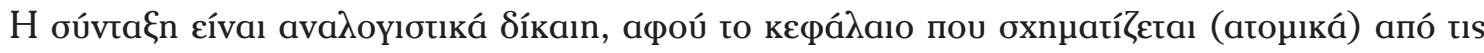

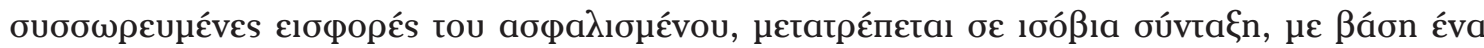

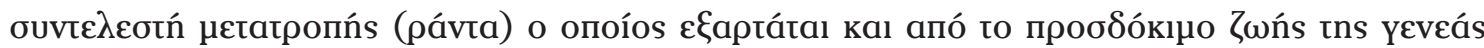

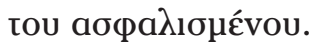

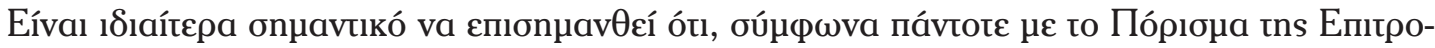

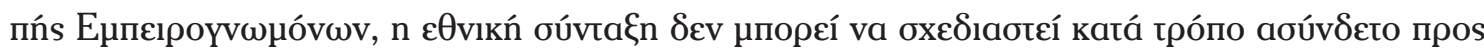

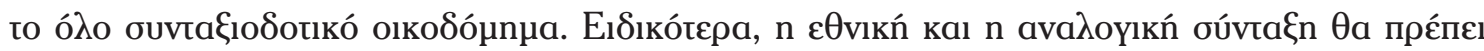

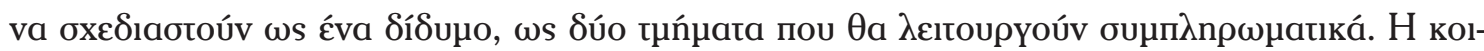

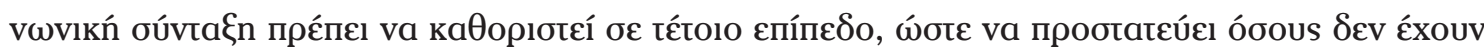

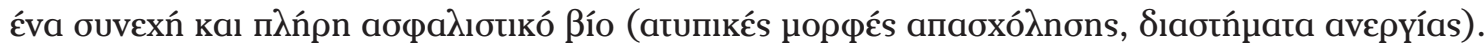

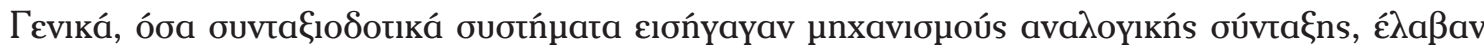

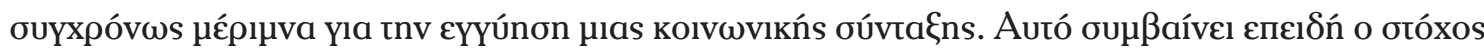

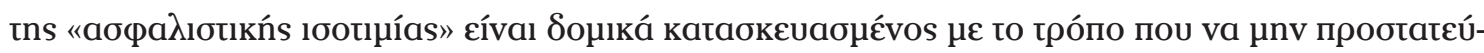

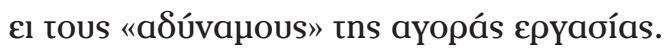

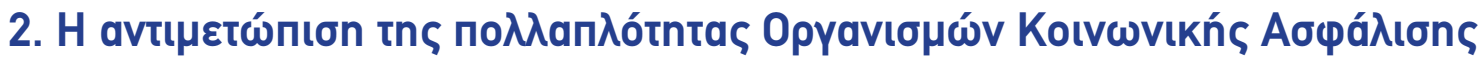

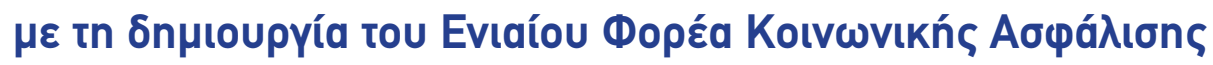

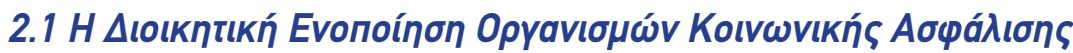

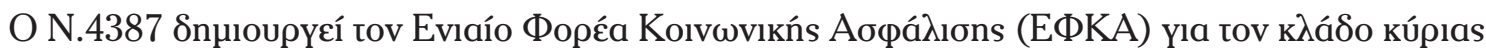

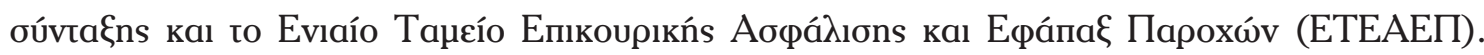

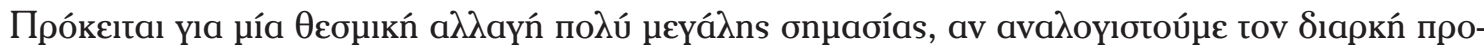

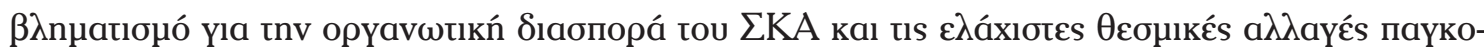

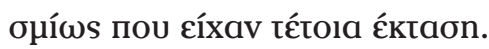

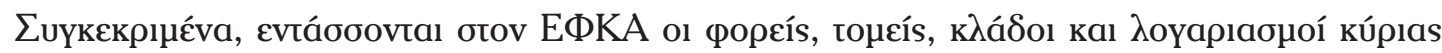

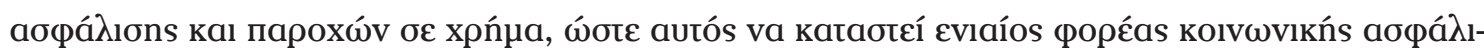

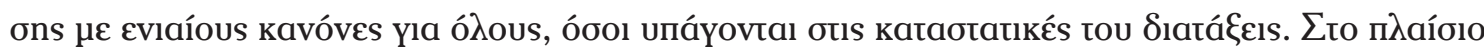

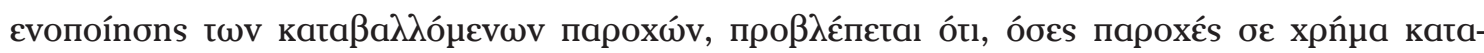

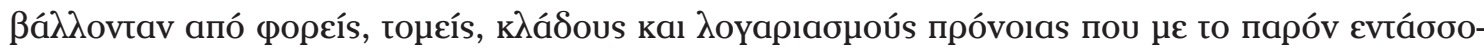
vтаı бто Е.Т.Е.А., Өа катаßа́ $\lambda \lambda$ ovtaı апó tov ЕФКА. 


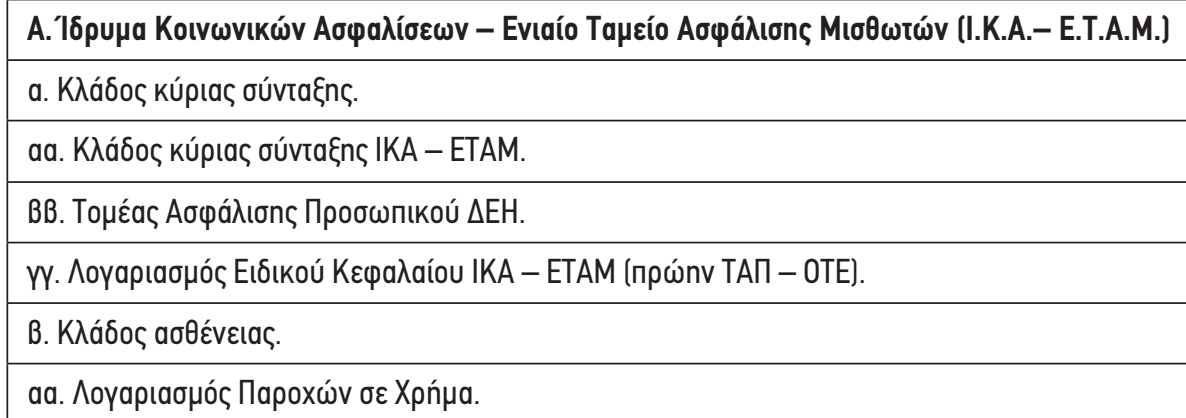

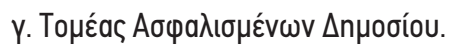

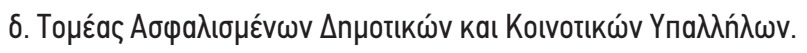

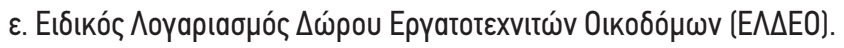

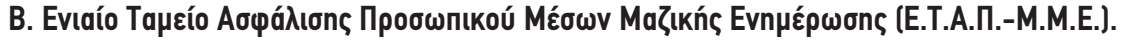

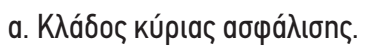

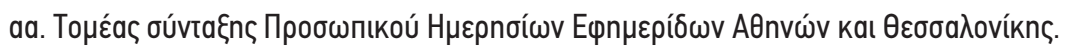

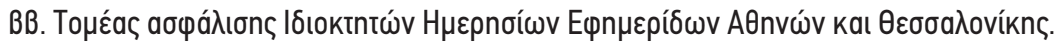

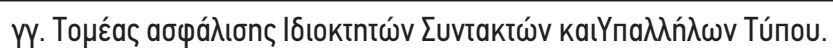

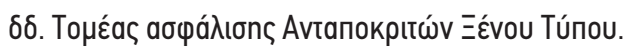

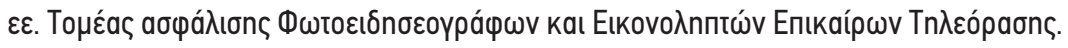

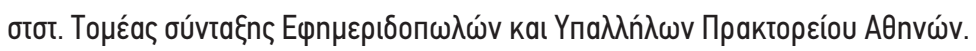

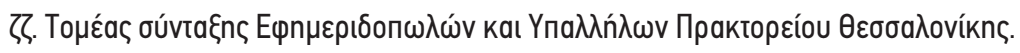

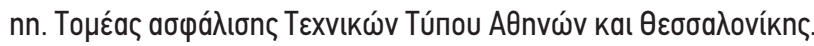

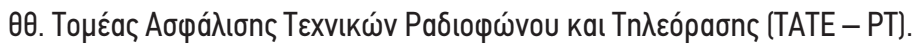

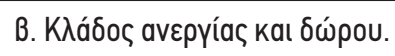

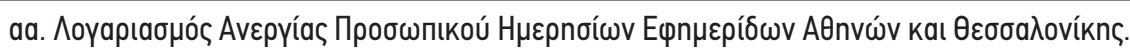

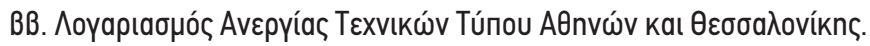

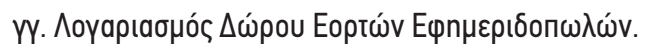

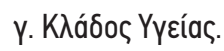

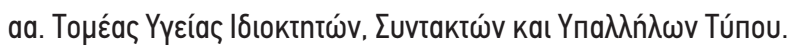

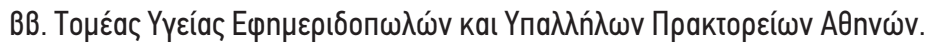

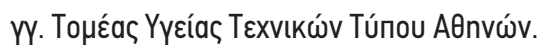

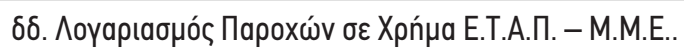

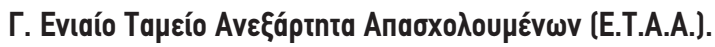

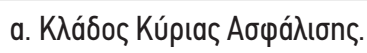

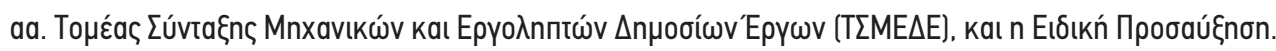

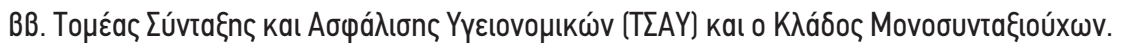




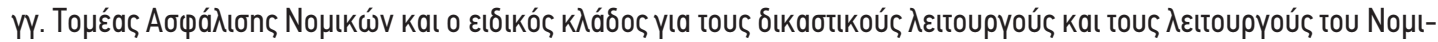

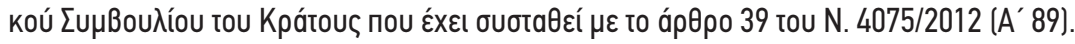

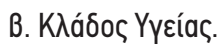

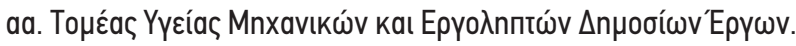

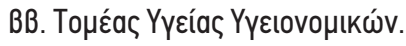

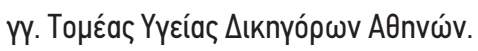

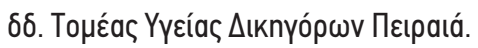

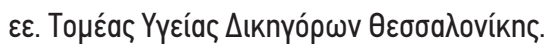

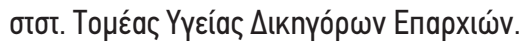

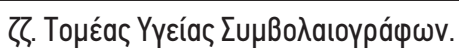

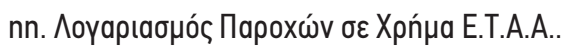

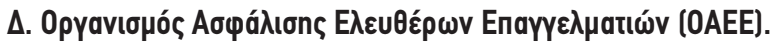

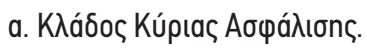

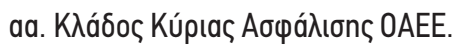

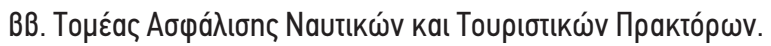

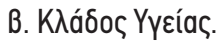

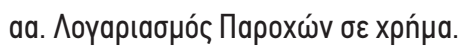

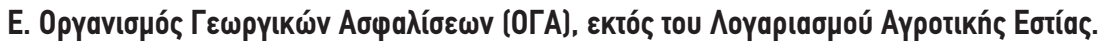

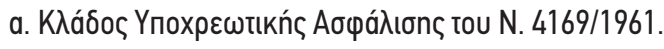

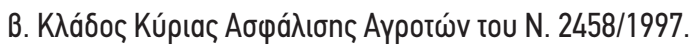

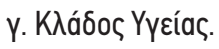

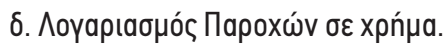

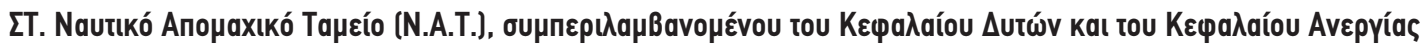

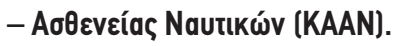

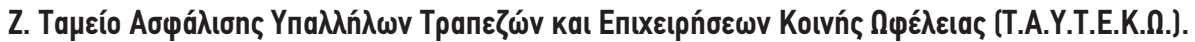

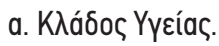

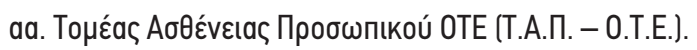

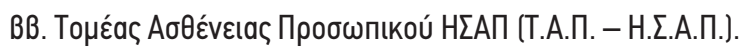

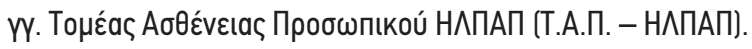

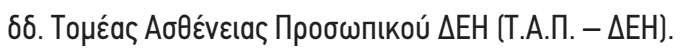

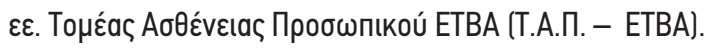

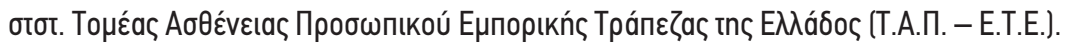

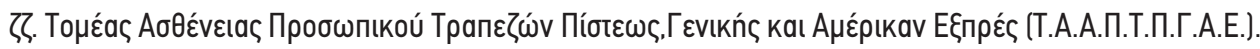

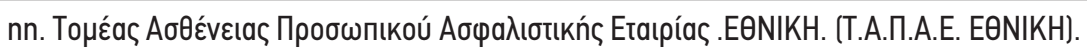

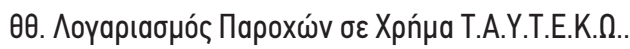

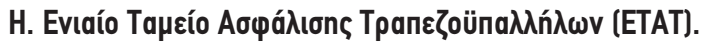




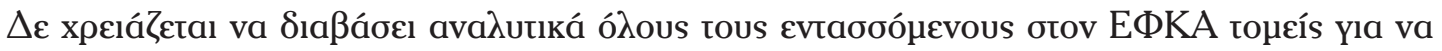

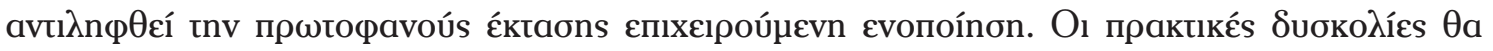

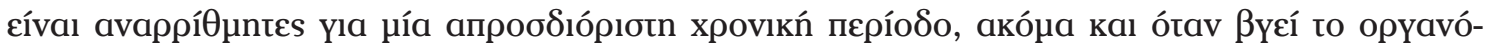

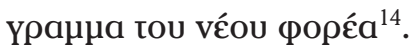

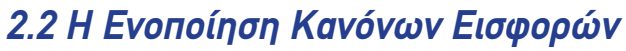

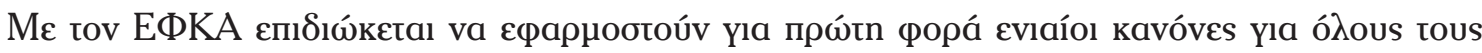

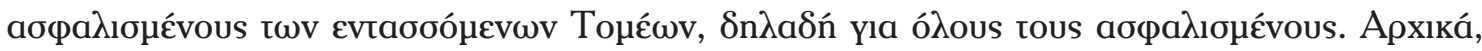

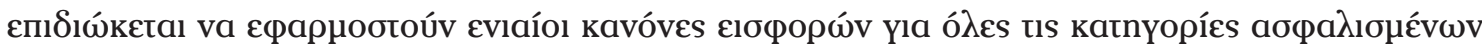

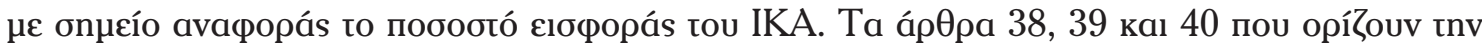

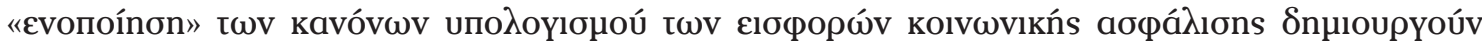

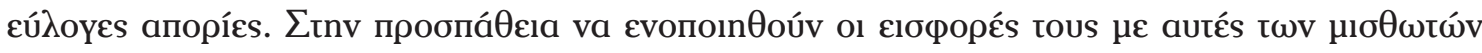

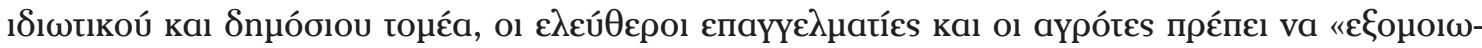

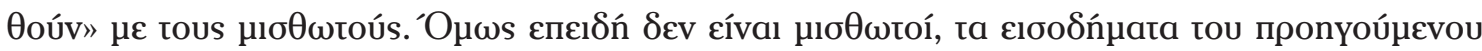

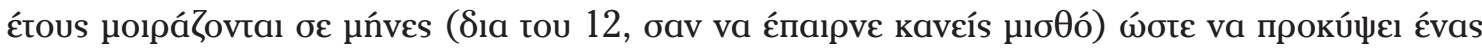

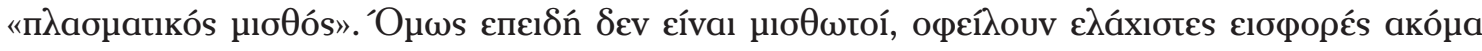

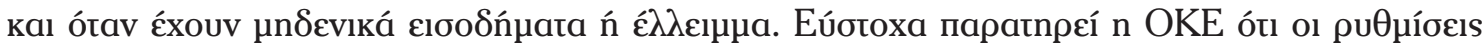

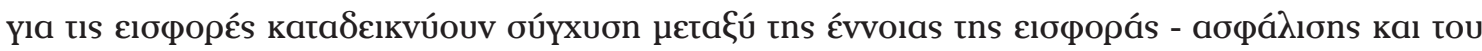

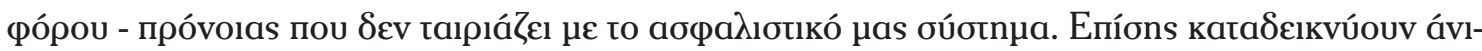

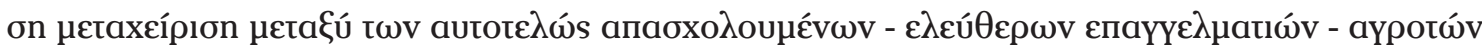

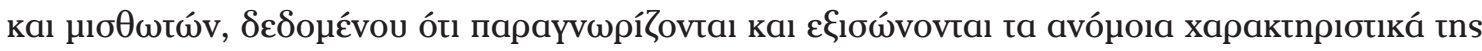

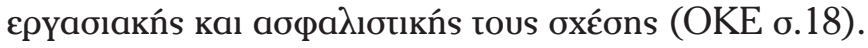

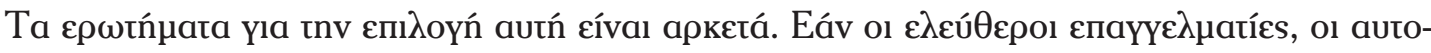

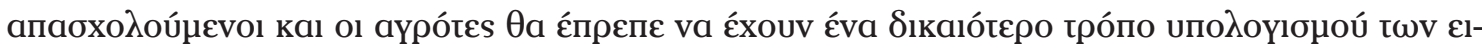

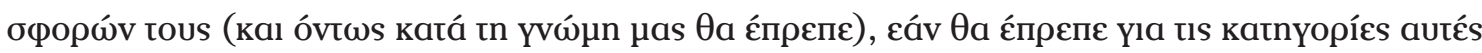

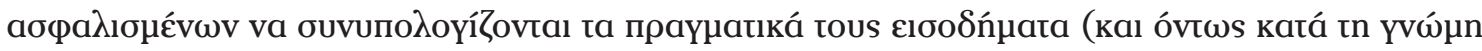

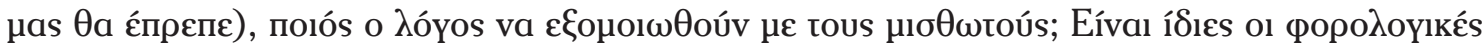

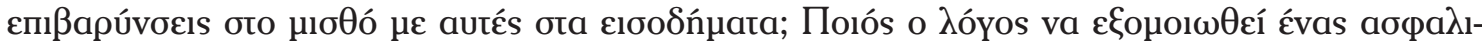

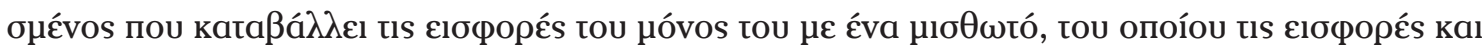

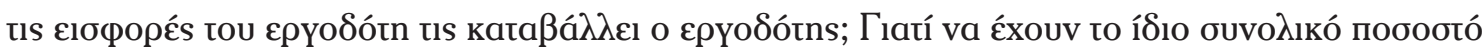

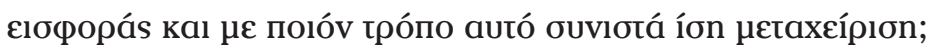

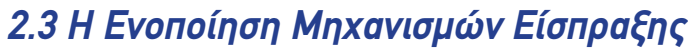

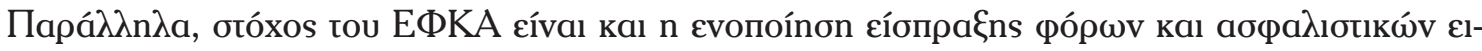

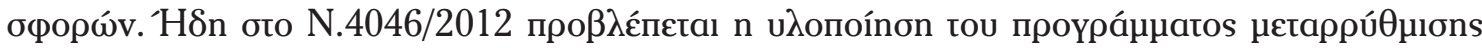

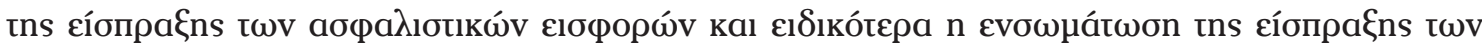

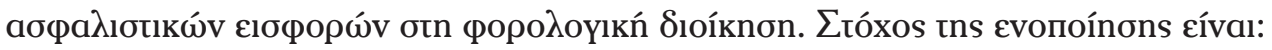

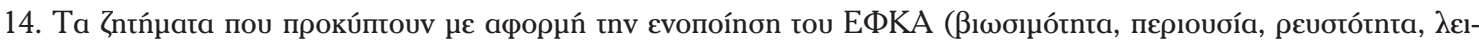

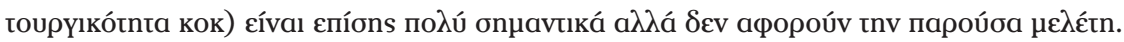




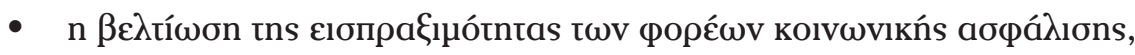

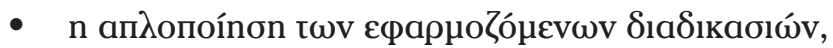

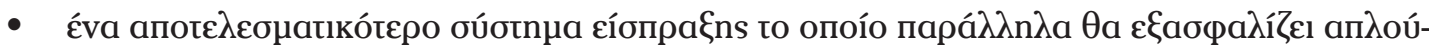

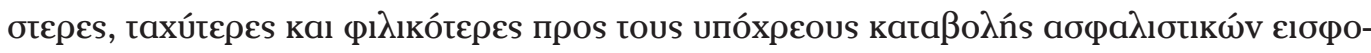

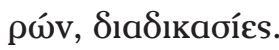

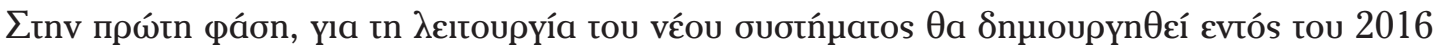

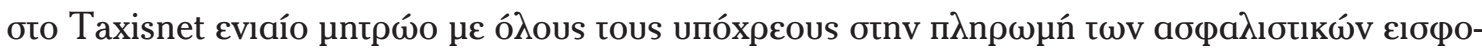

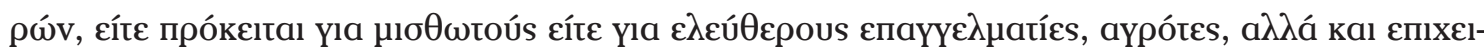

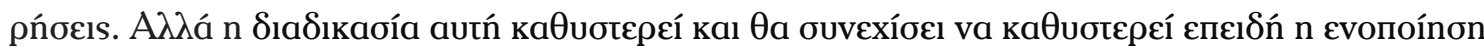

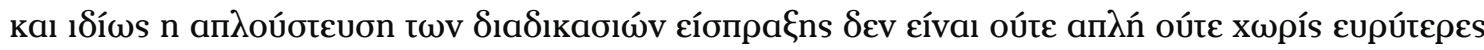

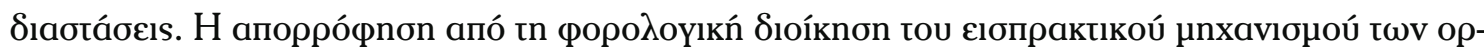

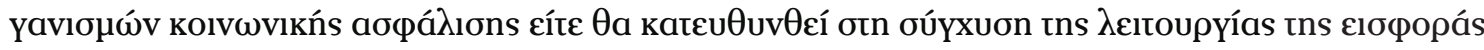

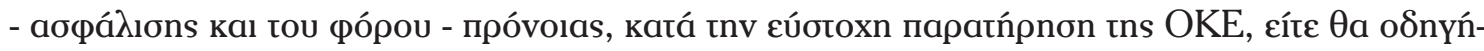

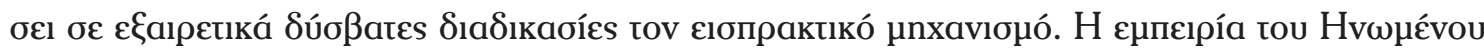

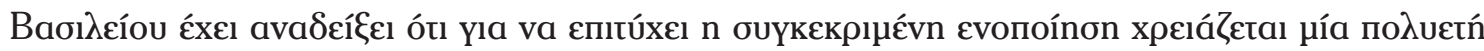

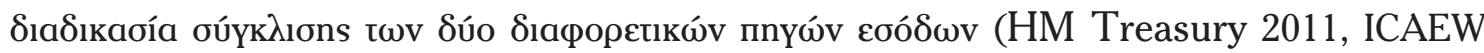
2015, Adam and Loutzenhiser 2007).

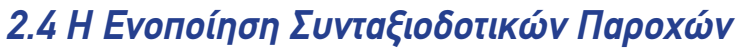

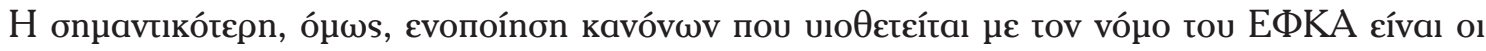

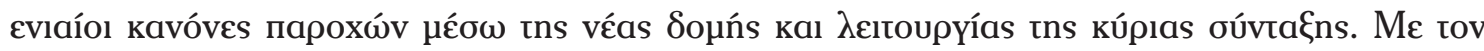

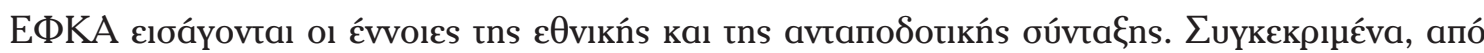

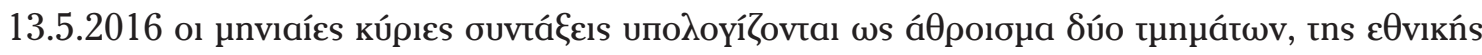

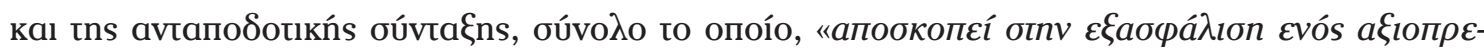

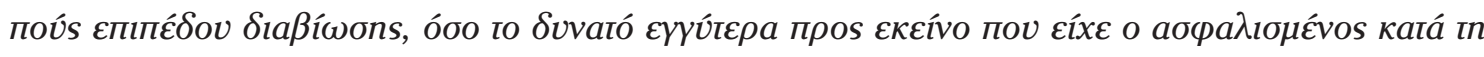

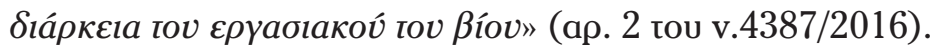

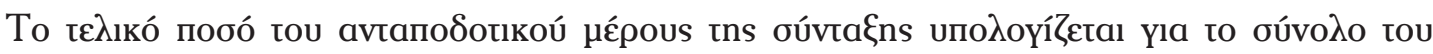

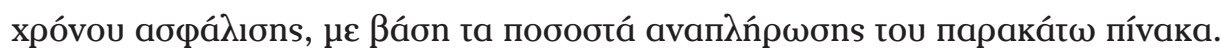




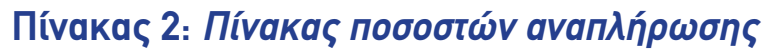

\begin{tabular}{|c|c|c|c|}
\hline \multicolumn{2}{|c|}{ 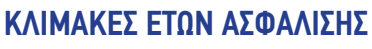 } & \multirow{2}{*}{ 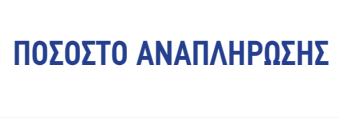 } & \multirow{2}{*}{ TEАIKO ПОГОГTO АNAПАНРОГНЕ } \\
\hline АПО & E $\Omega \Sigma$ & & \\
\hline 0 & 15 & $0,77 \%$ & $11,55 \%$ \\
\hline 15,01 & 16 & \multirow{3}{*}{$0,84 \%$} & $12,39 \%$ \\
\hline 16,01 & 17 & & $13,23 \%$ \\
\hline 17,01 & 18 & & $14,07 \%$ \\
\hline 18,01 & 19 & \multirow{3}{*}{$0,90 \%$} & $14,97 \%$ \\
\hline 19,01 & 20 & & $15,87 \%$ \\
\hline 20,01 & 21 & & $16,77 \%$ \\
\hline 21,01 & 22 & \multirow{3}{*}{$0,96 \%$} & $17,73 \%$ \\
\hline 22,01 & 23 & & $18,69 \%$ \\
\hline 23,01 & 24 & & $19,65 \%$ \\
\hline 24,01 & 25 & \multirow{3}{*}{$1,03 \%$} & $20,68 \%$ \\
\hline 25,01 & 26 & & $21,71 \%$ \\
\hline 26,01 & 27 & & $22,74 \%$ \\
\hline 27,01 & 28 & \multirow{3}{*}{$1,21 \%$} & $23,95 \%$ \\
\hline 28,01 & 29 & & $25,16 \%$ \\
\hline 29,01 & 30 & & $26,37 \%$ \\
\hline 30,01 & 31 & \multirow{3}{*}{$1,42 \%$} & $27,79 \%$ \\
\hline 31,01 & 32 & & $29,21 \%$ \\
\hline 32,01 & 33 & & $30,63 \%$ \\
\hline 33,01 & 34 & \multirow{3}{*}{$1,59 \%$} & $32,22 \%$ \\
\hline 34,01 & 35 & & $33,81 \%$ \\
\hline 35,01 & 36 & & $35,40 \%$ \\
\hline 36,01 & 37 & \multirow{3}{*}{$1,80 \%$} & $37,20 \%$ \\
\hline 37,01 & 38 & & $39 \%$ \\
\hline 38,01 & 39 & & $40,80 \%$ \\
\hline 39,01 & 40 & \multirow{3}{*}{$2,00 \%$} & $42,80 \%$ \\
\hline 40,01 & 41 & & $44,80 \%$ \\
\hline 41,01 & 42 kaı ávw & & $46,80 \%$ \\
\hline
\end{tabular}

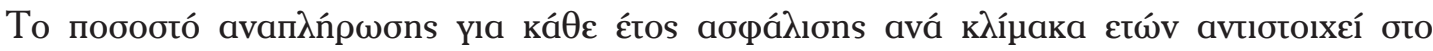

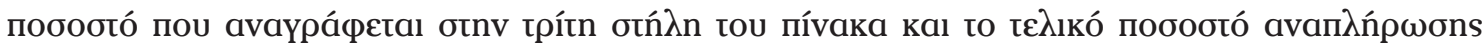

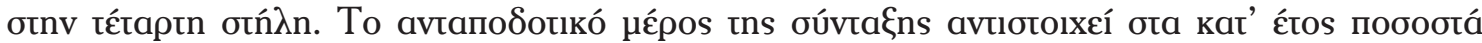

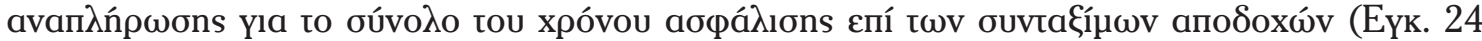
EФKA, 22/05/2017). 


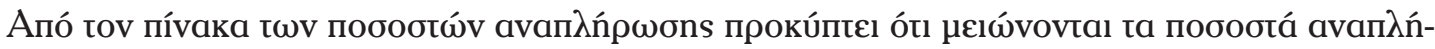

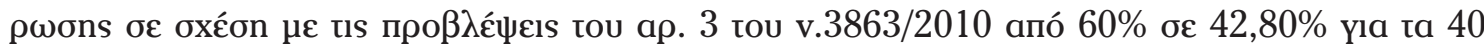

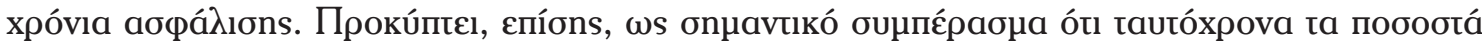

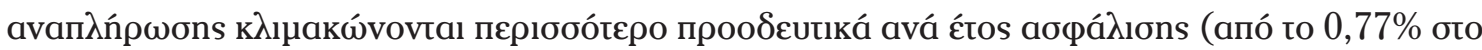

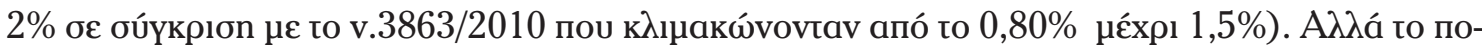

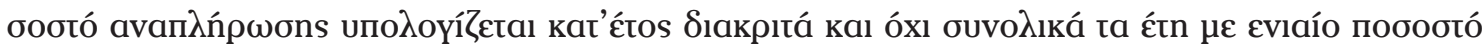

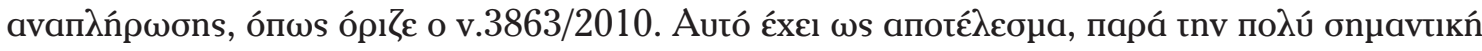

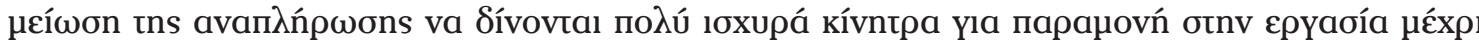
ta 40 xpóvia.

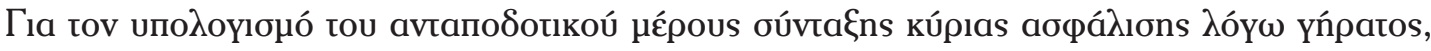

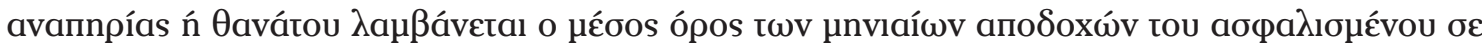

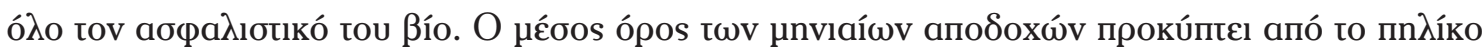

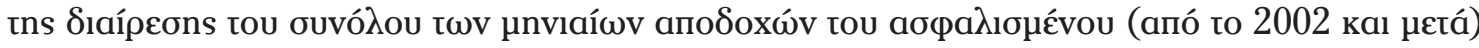

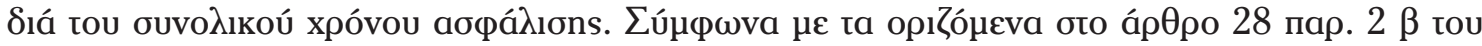

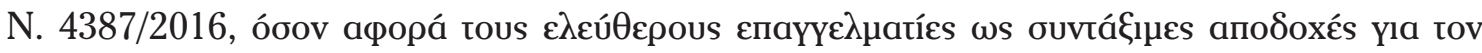

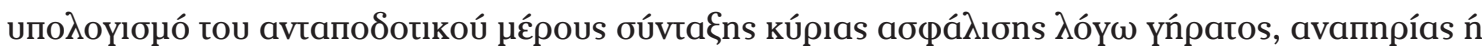

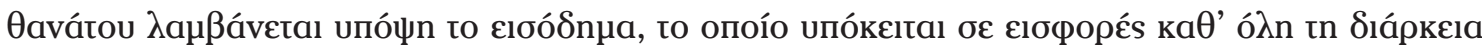
tou абчаגıбıкои́ ßíou.

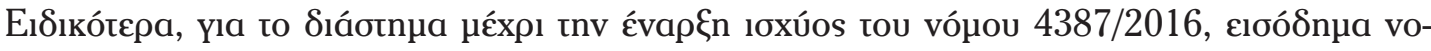

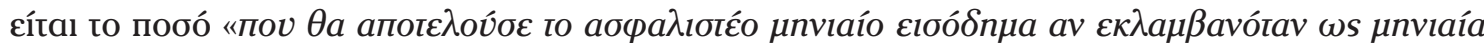

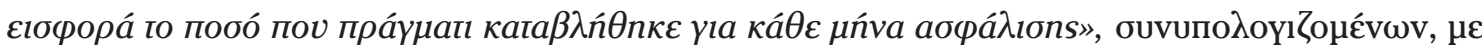

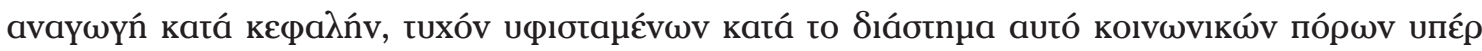

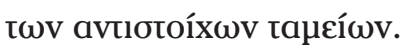

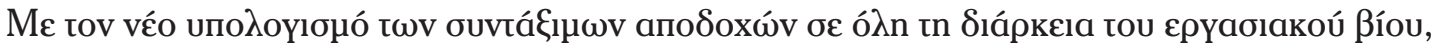

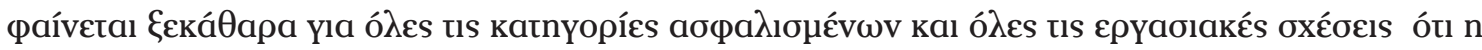

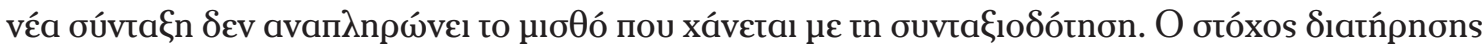

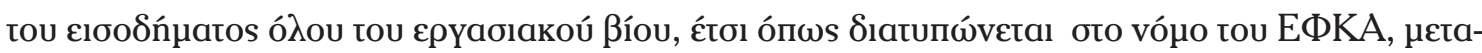

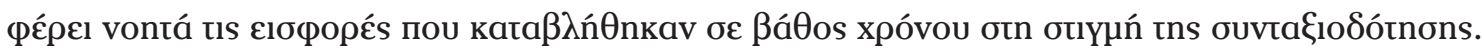

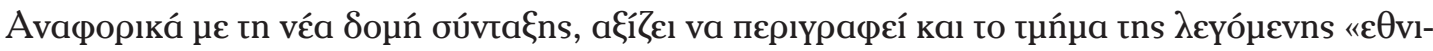

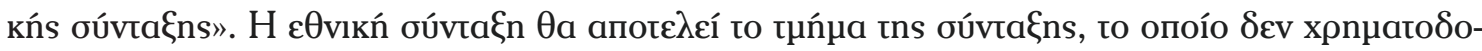

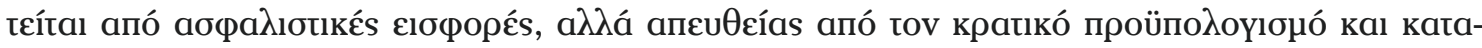

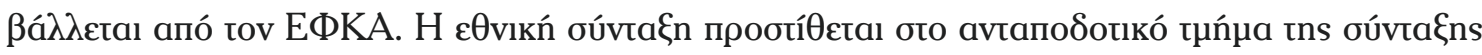

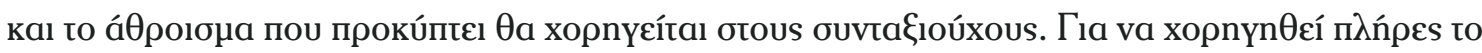

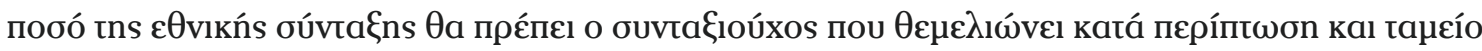

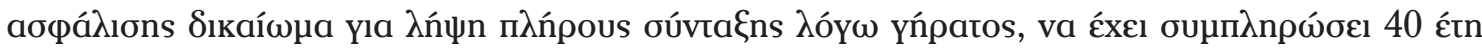

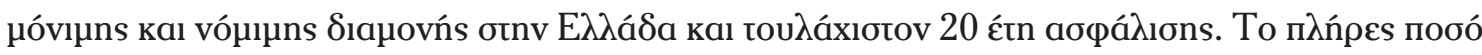

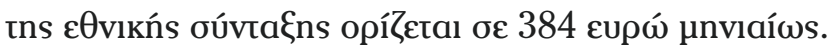

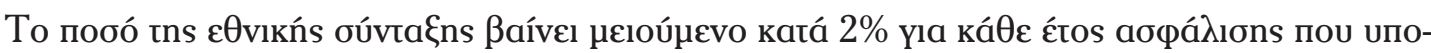

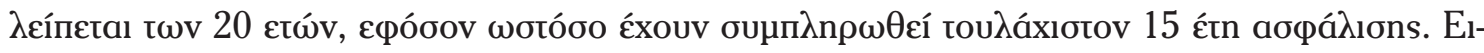
ठıќ́єра:

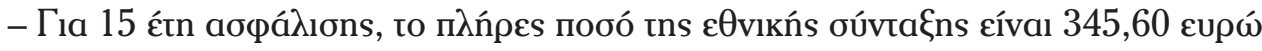

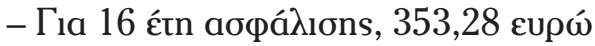




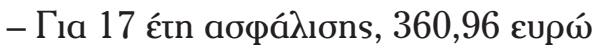

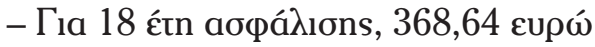

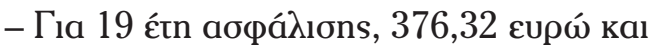

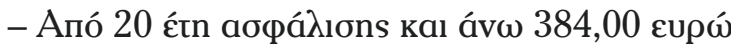

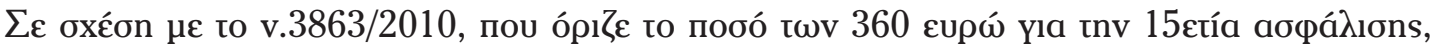

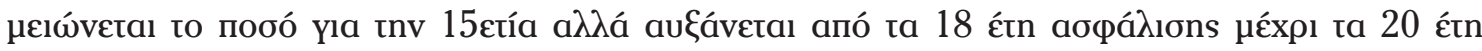

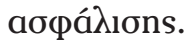

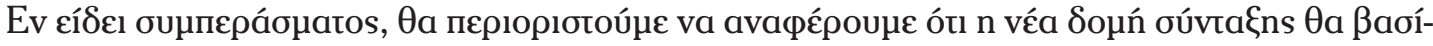

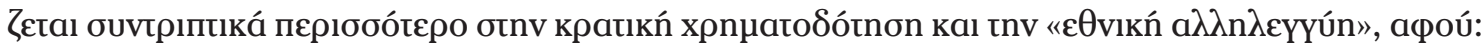

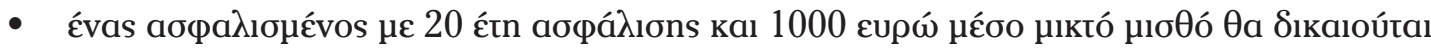

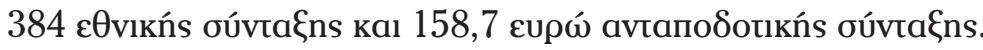

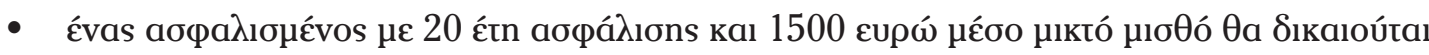

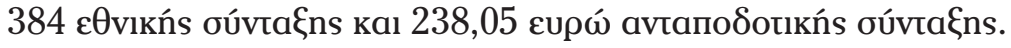

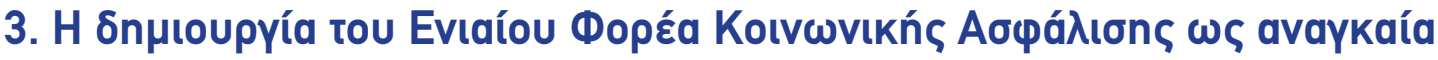

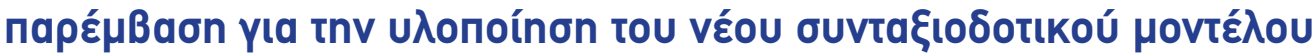

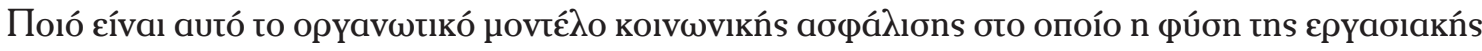

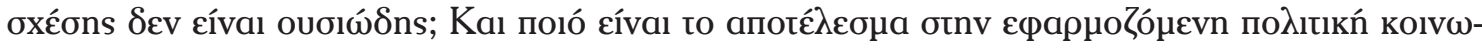

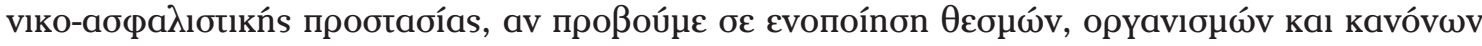

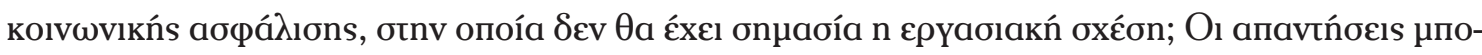

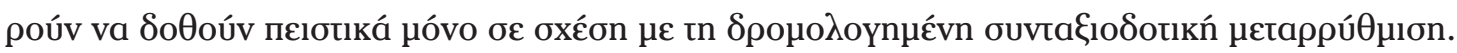

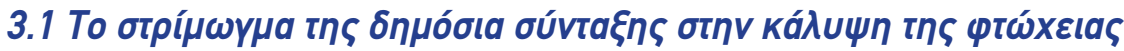

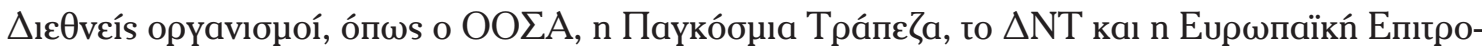

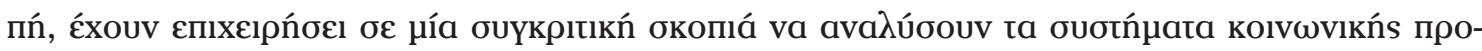

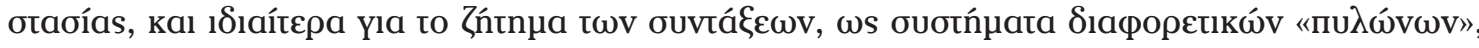

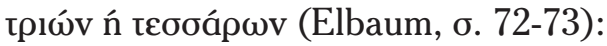

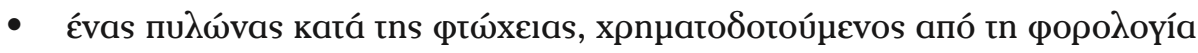

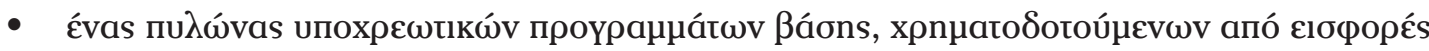

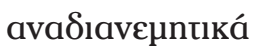

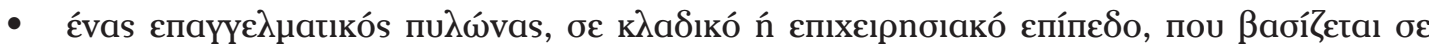

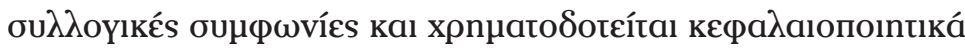

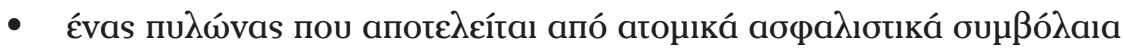

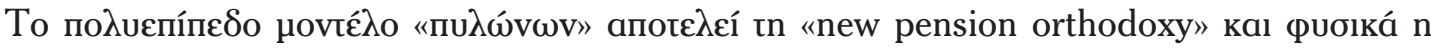

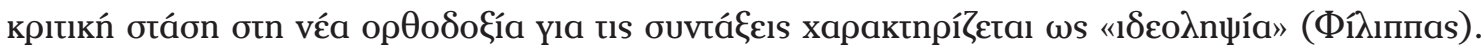

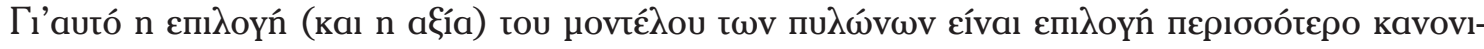

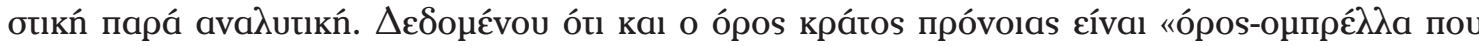




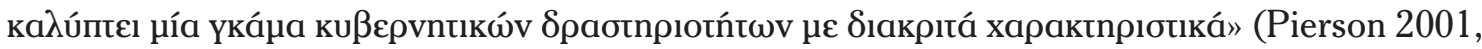

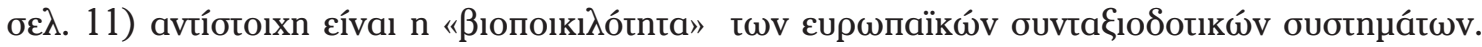

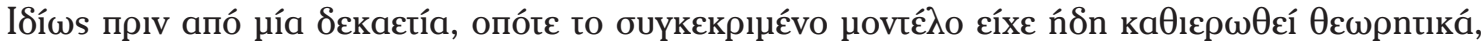

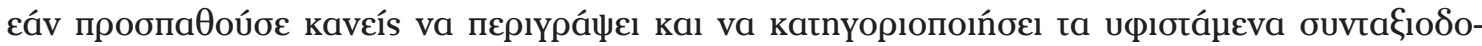

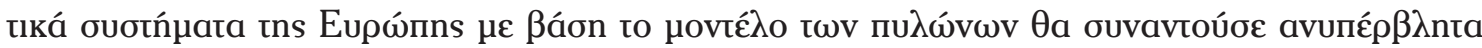

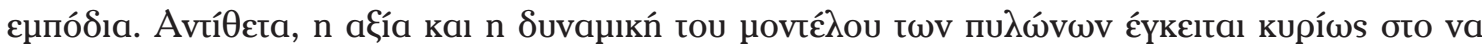

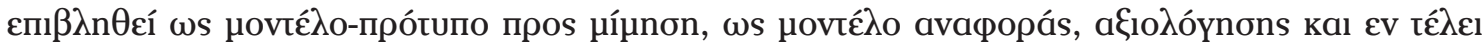

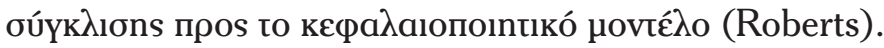

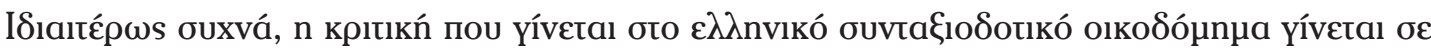

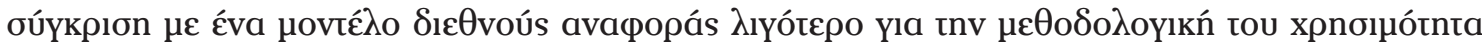

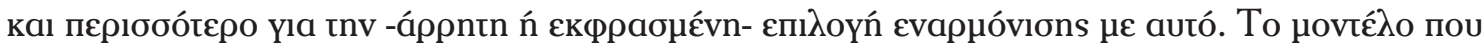

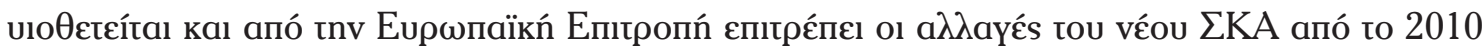

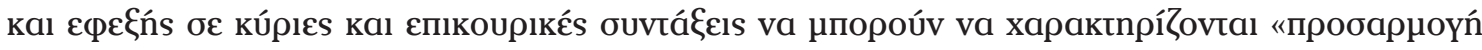

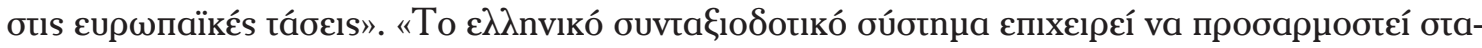

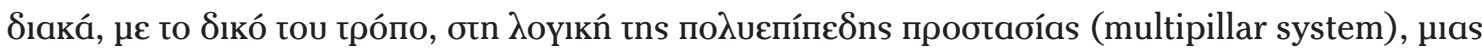

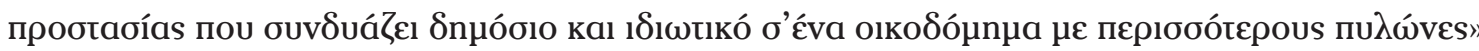

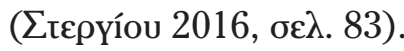

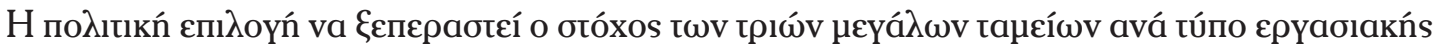

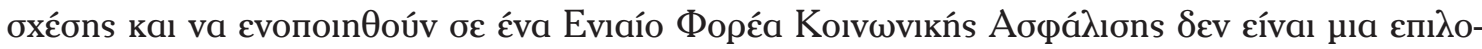

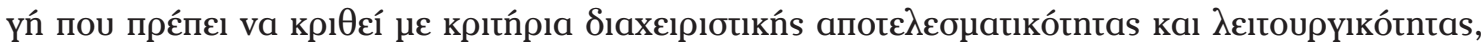

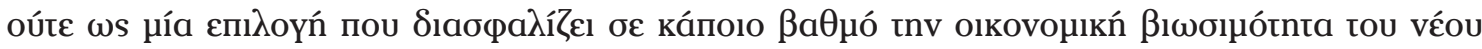

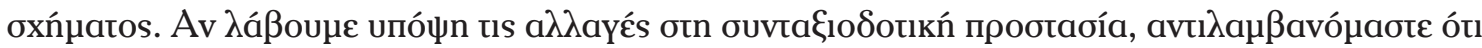

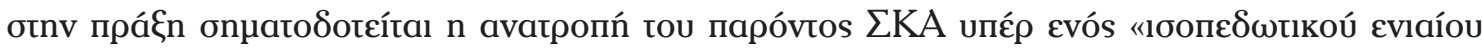

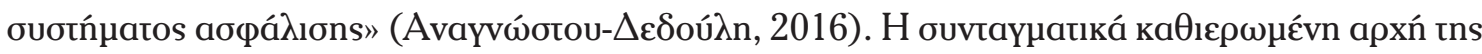

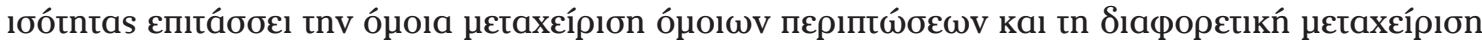

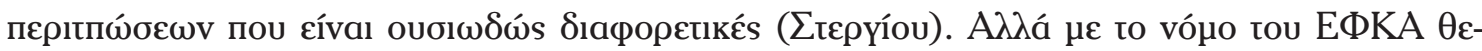

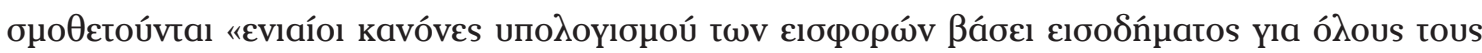

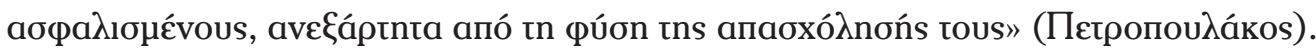

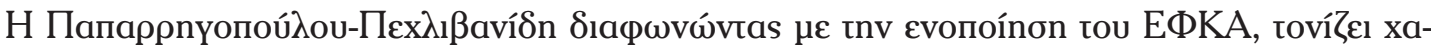

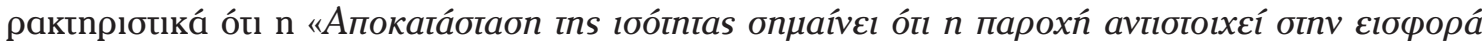

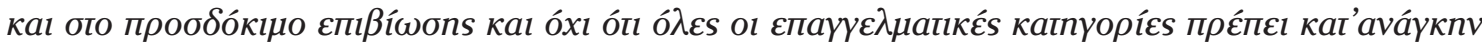

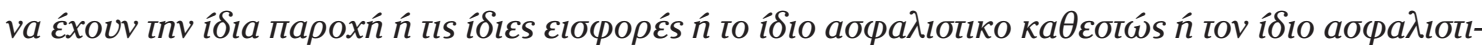

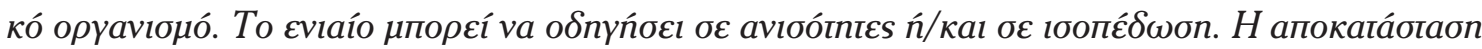

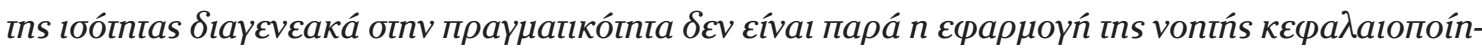

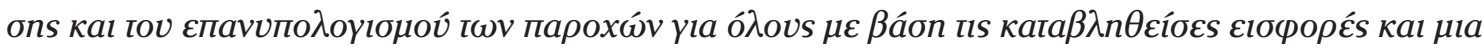

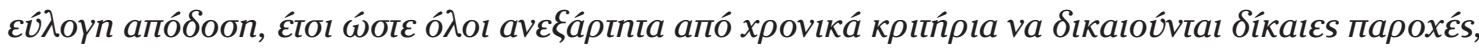

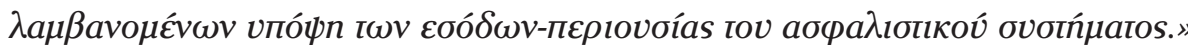

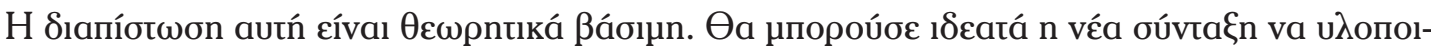

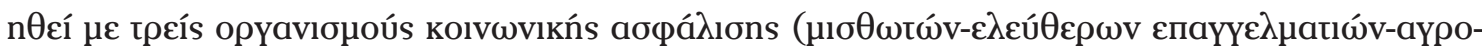

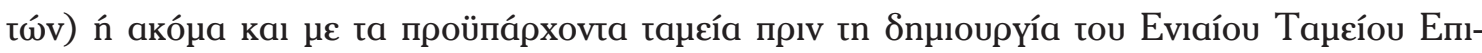

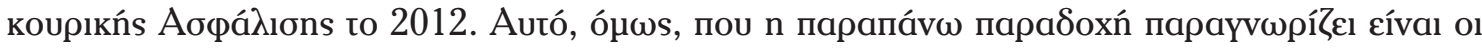

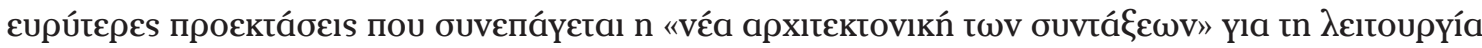




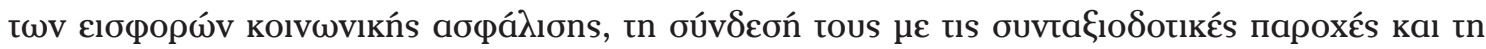

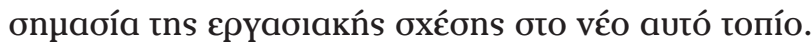

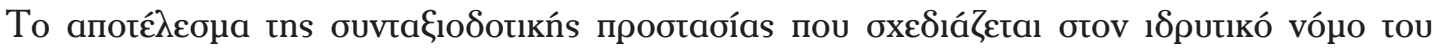

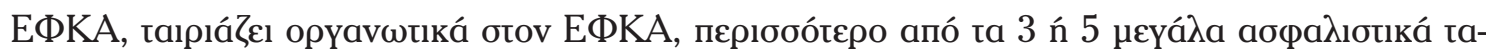

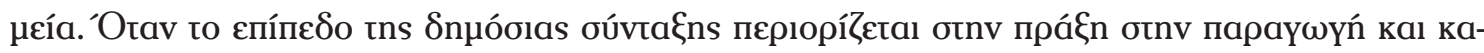

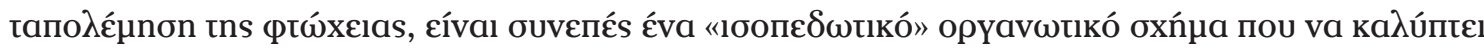

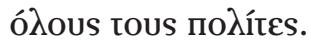

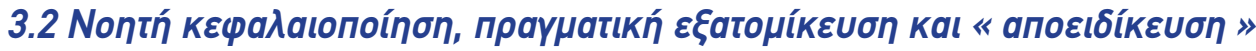

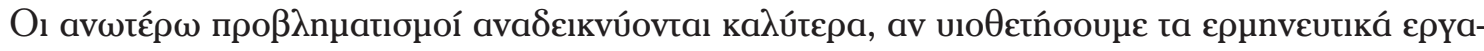

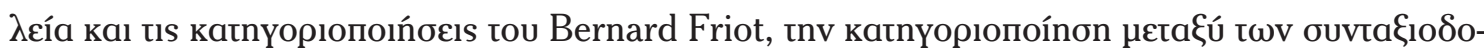

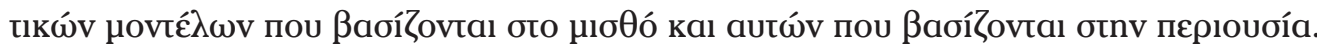

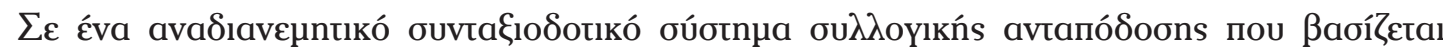

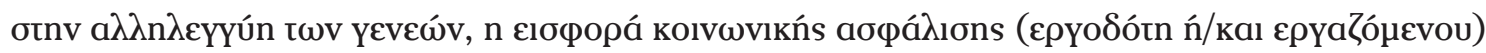

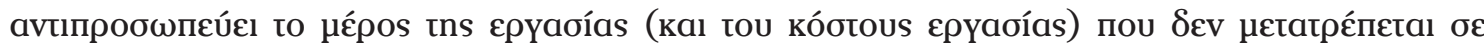

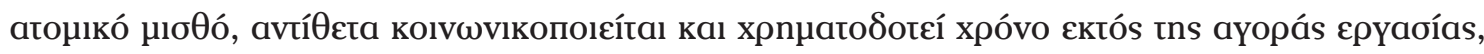

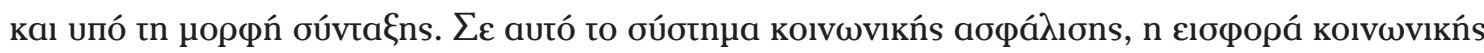

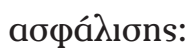

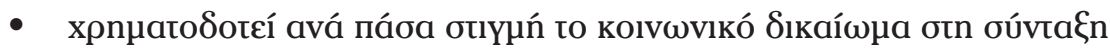

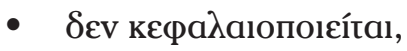

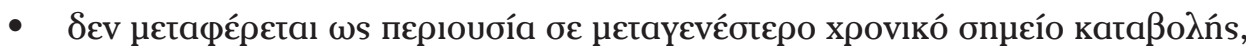

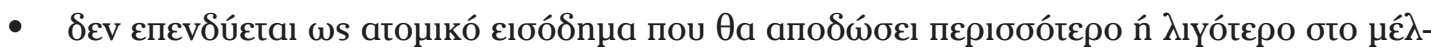
$\lambda$ ov.

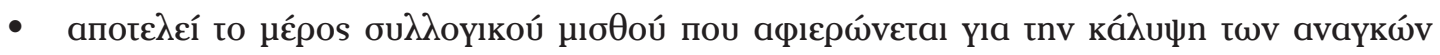

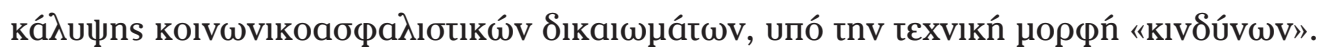

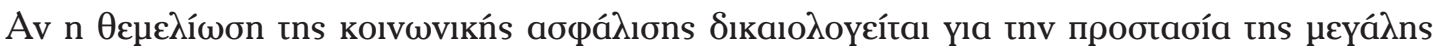

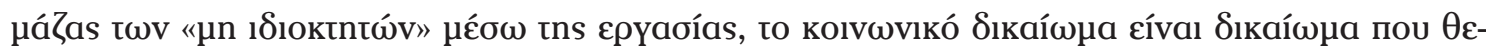

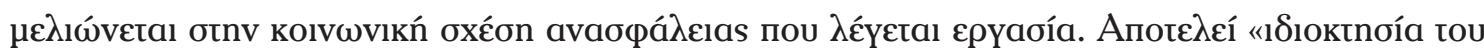

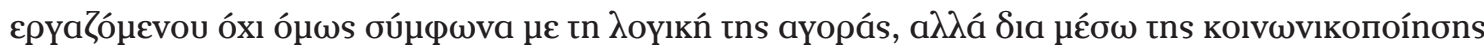

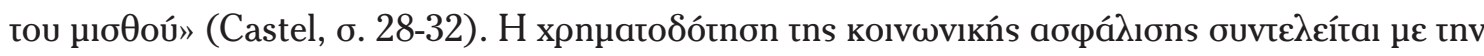

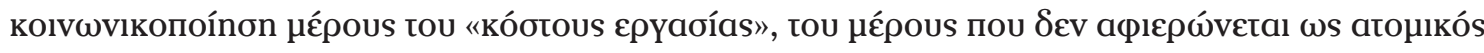

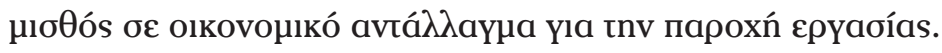

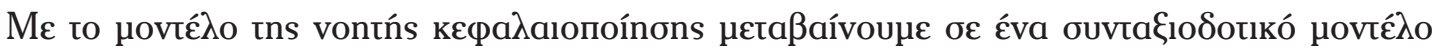

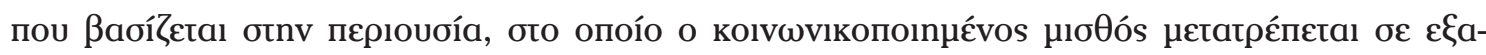

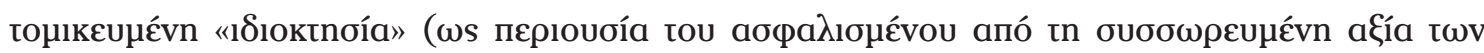

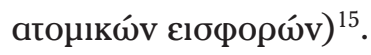

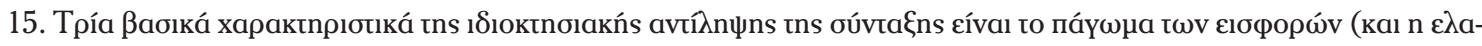

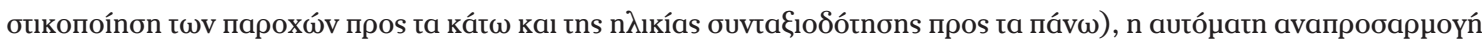

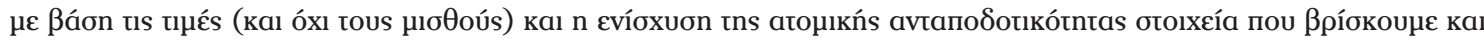

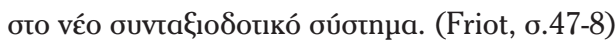




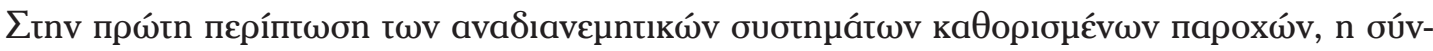

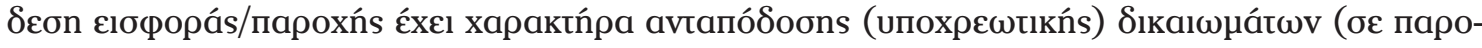

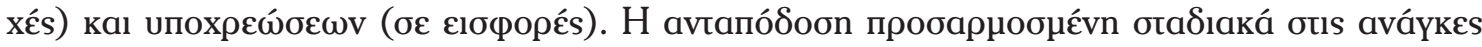

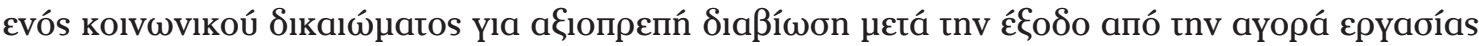

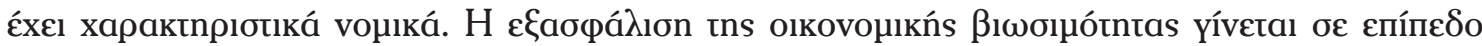

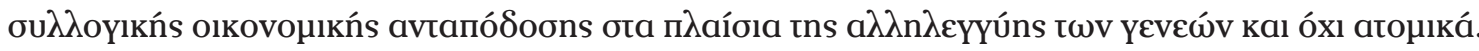

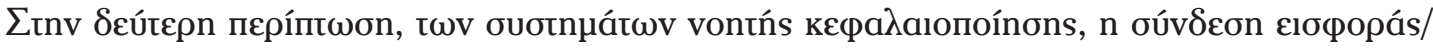

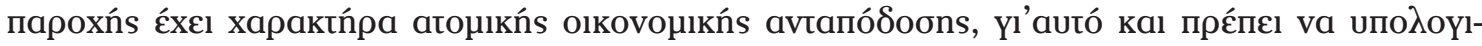

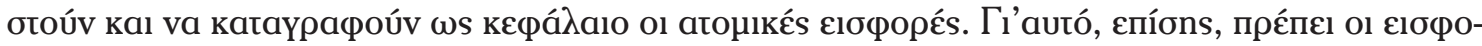

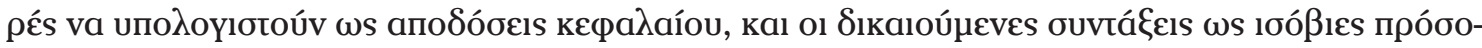

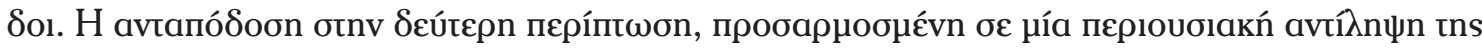

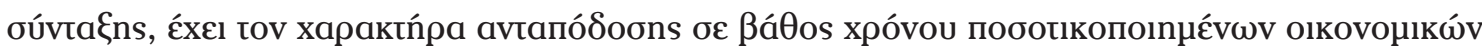

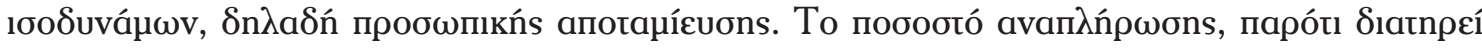

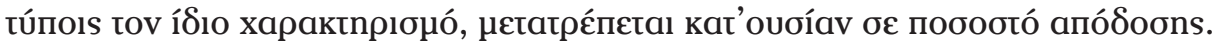

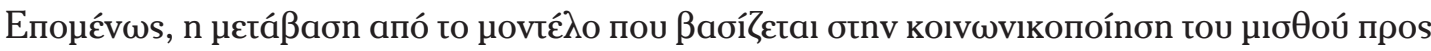

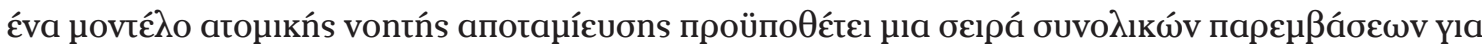

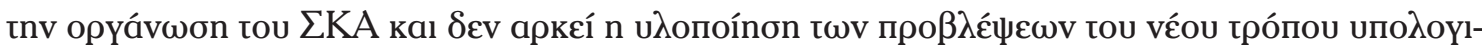

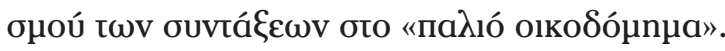

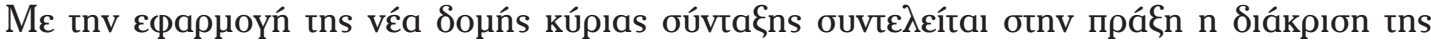

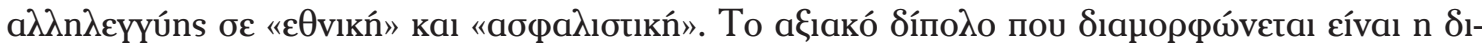

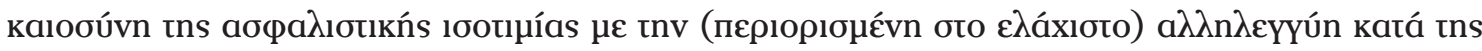

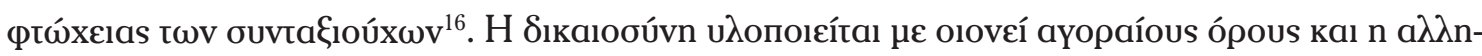

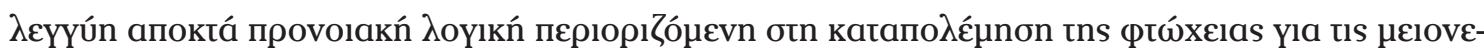

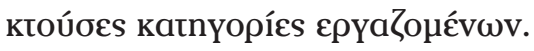

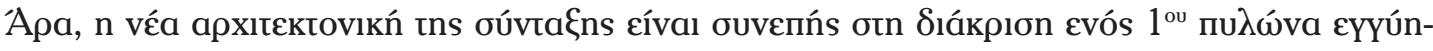

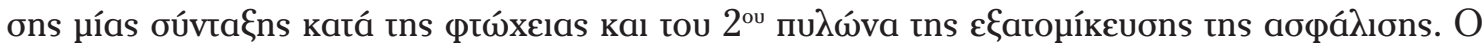

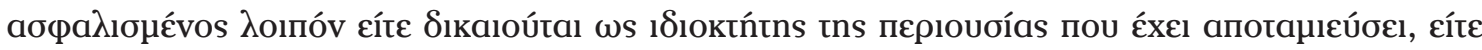

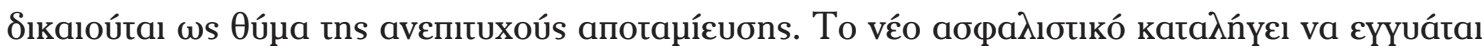

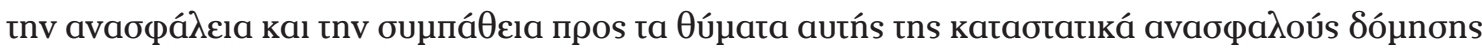

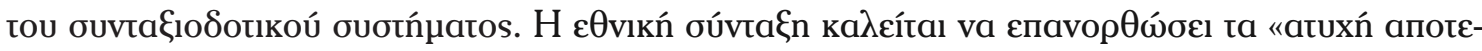

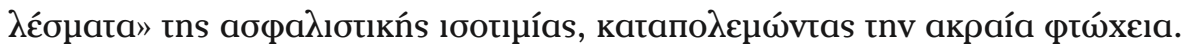

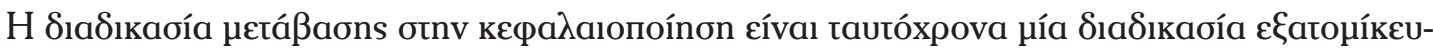

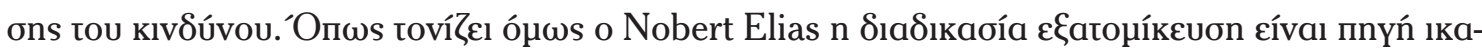

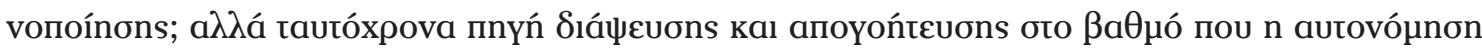

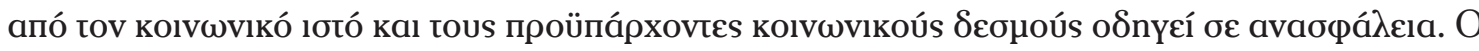

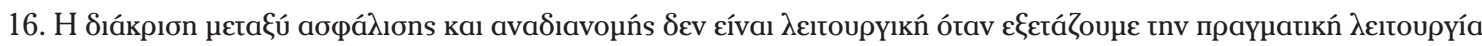

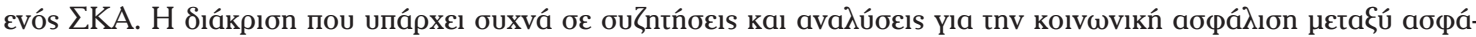

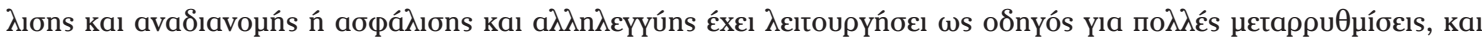

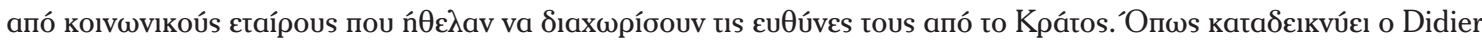

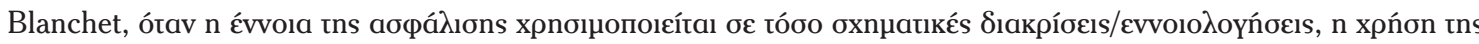

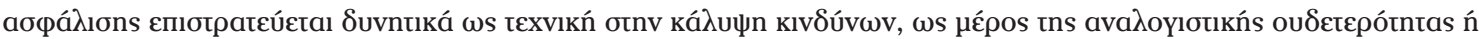

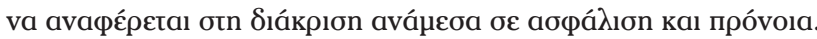




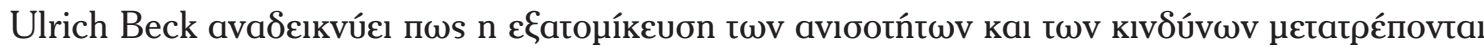

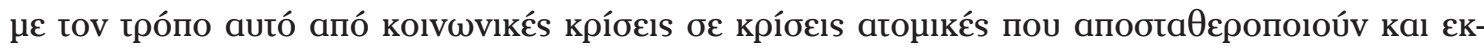

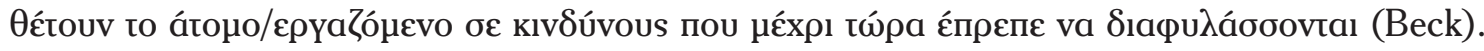

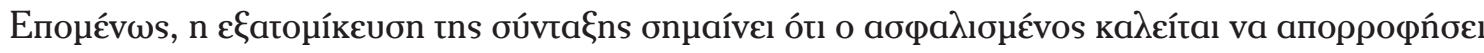

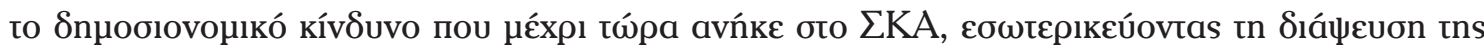

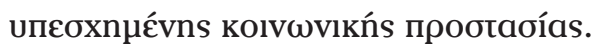

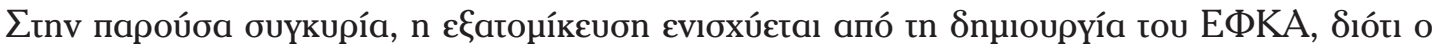

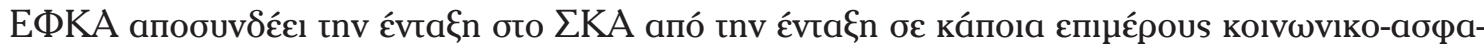

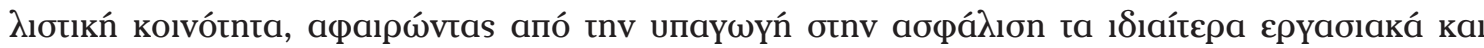

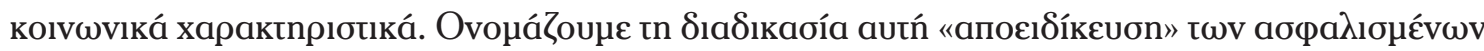

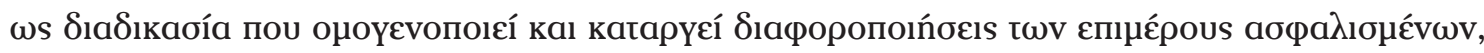

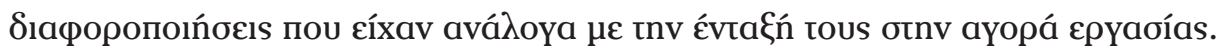

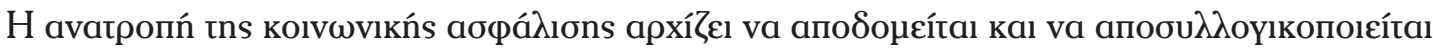

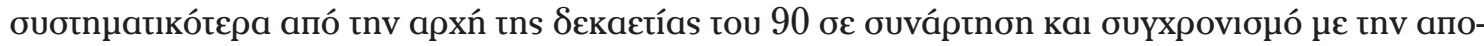

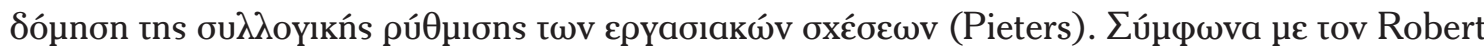

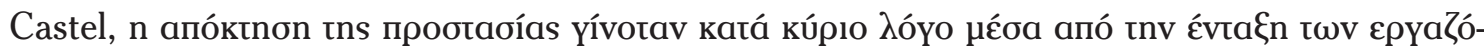

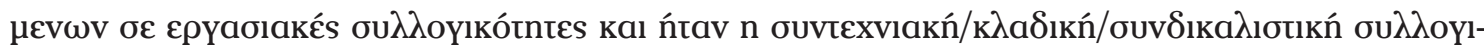

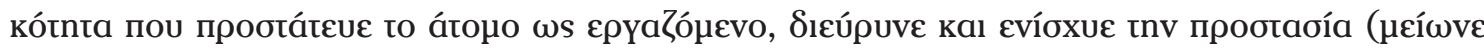

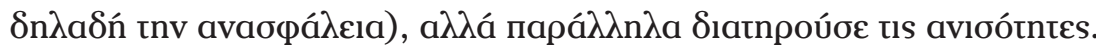

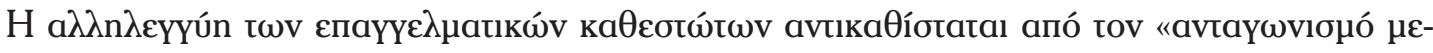

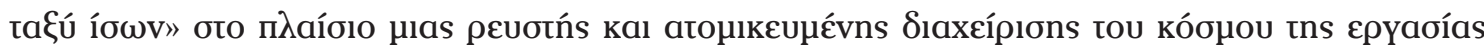

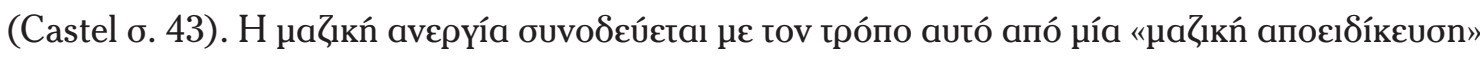

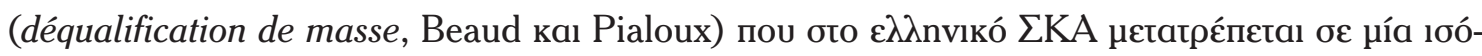

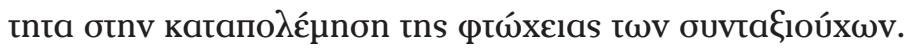

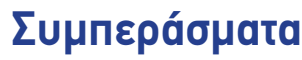

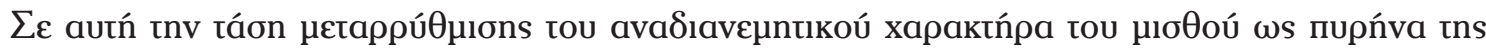

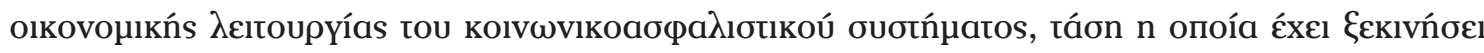

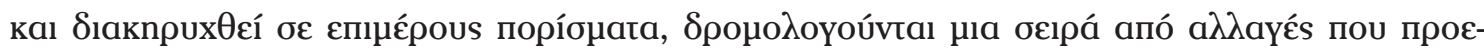

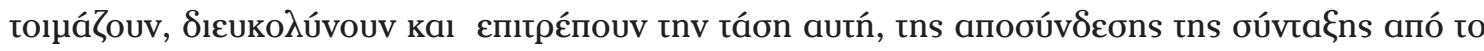

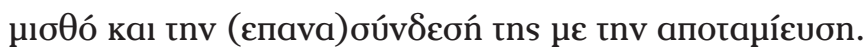

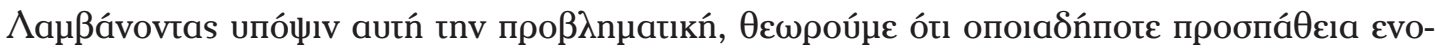

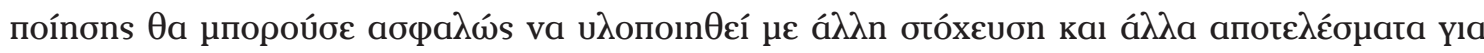

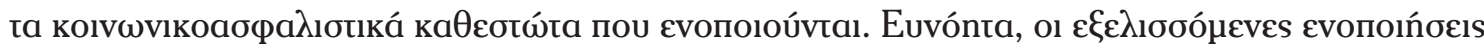

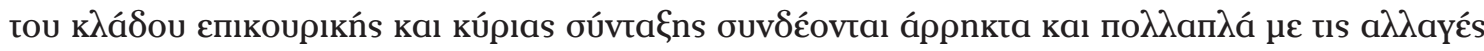

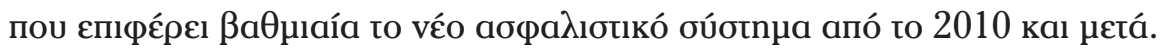

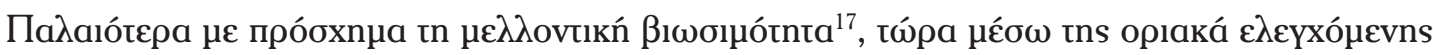

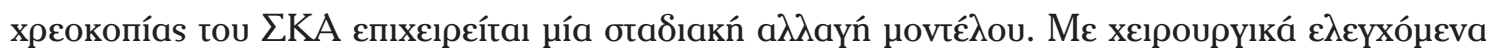

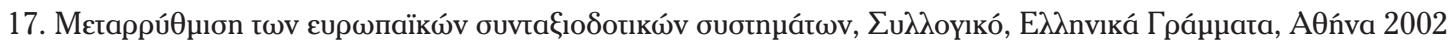




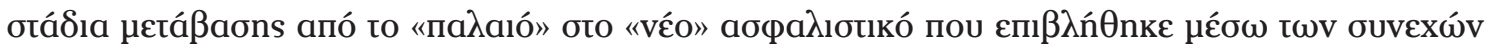

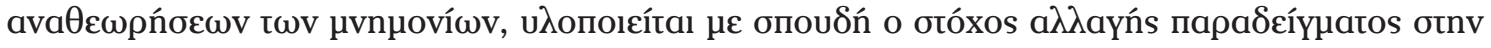

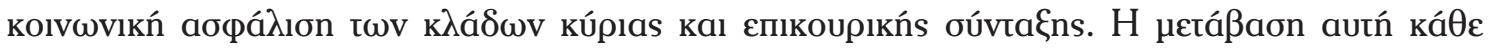

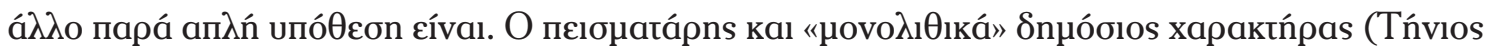

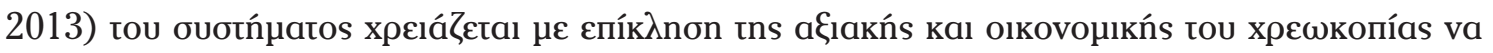

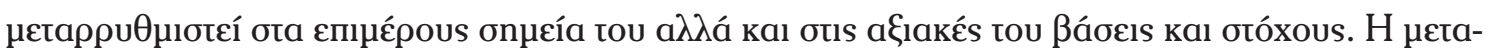

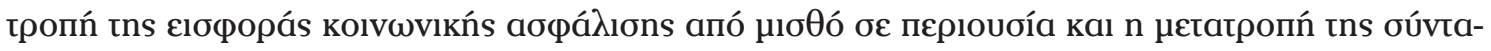

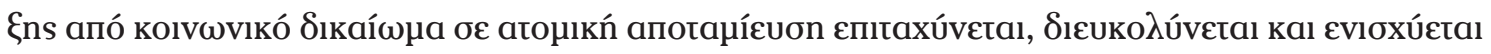

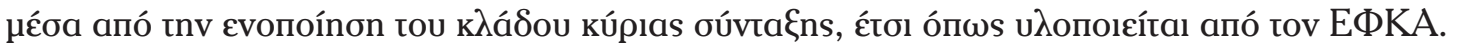

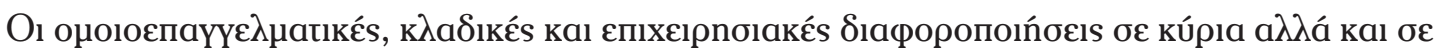

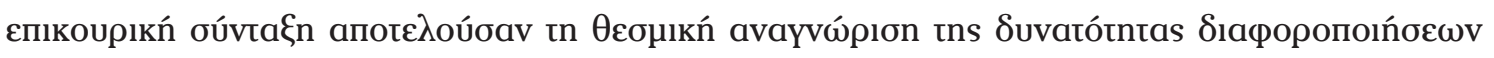

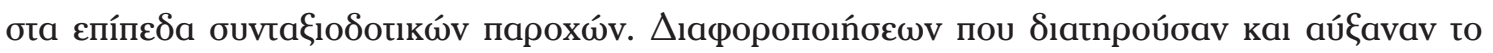

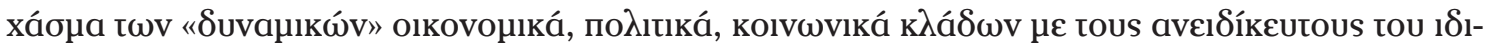

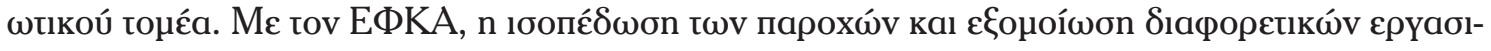

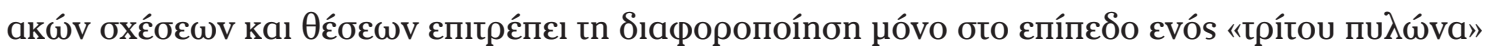

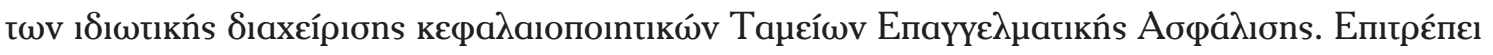

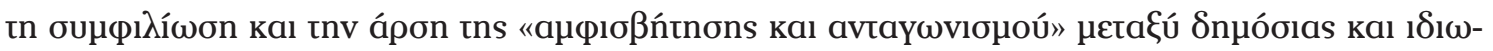

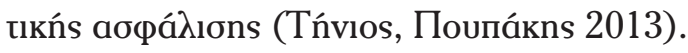

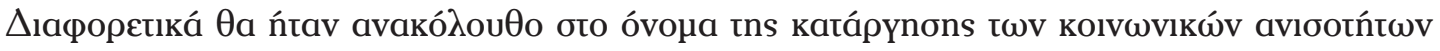

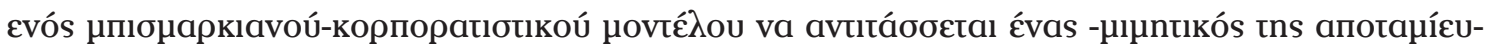

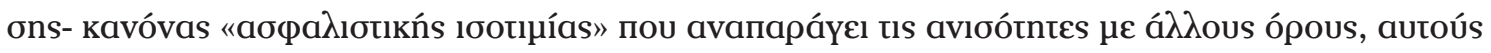
tns ayopás.

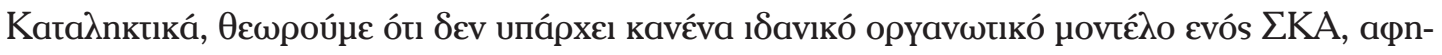

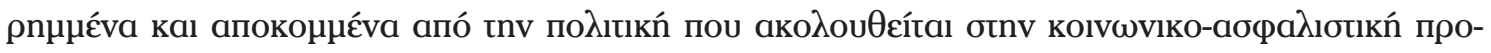

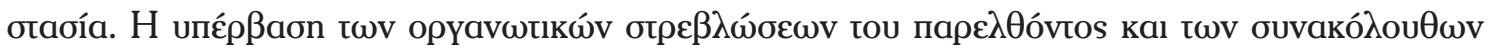

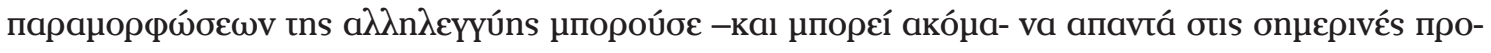

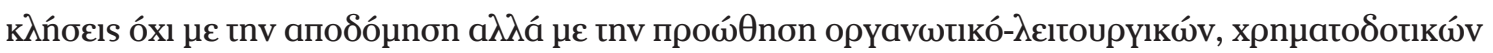

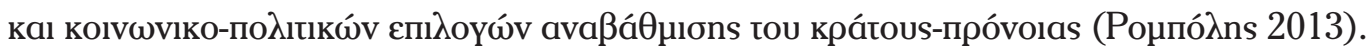

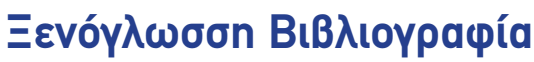

\section{- Papers in Journal}

Blanchet D., (1996) «La référence assurantielle en matière de protection sociale : apports et limites», Économie et Statistique, no 291-292

Caradec V., (2009), « Retraite « à la carte » et « libre choix » individuel. Réflexion sur les transformations contemporaines de la retraite », Gérontologie et société, 32 / n 131, pp. 25-43.

Pierson P., (1998) «Irresistible forces, immovable objects : post-industrial welfare states confront permanent austerity ", Journal of European Public Policy, 5, pp. 539-560

Palme J., (2005) "Features of the Swedish pension reform », The Japanese Journal of Social Security Policy, Vol.4, No.1 
Roberts L., (2007) «Les logiques des systèmes de retraite en Europe », Retraite et Société, no 50 Supiot A., (2014), "Au fondement de la citoyenneté sociale, $\mathrm{Ni}$ assurance ni charité, la solidarité», Le Monde Diplomatique

\section{- Papers in edited books}

Beck Ul., (2001) «La société du risque. Sur la voie d'une autre modernité», Paris, Aubier

Donzelot J., (1994) «L'invention du social, Essai sur le déclin des passions politiques», éd. Seuil

Elias N., (1997) «La société des individus», Paris, Agora

Cusset P.Y., (2007), Le lien social, ed. Armand Colin, Paris

Elbaum M., (2008) «Économie Politique de la protection sociale», PUF

Friot B., (2010) L'enjeu des retraites, La Dispute

Hinricks K. (2001), «Elephants on the move. Patterns of public pension reform in OECD countries ", in Leibfried S., Welfare State Futures, Cambridge University Press, pp. 77-102

Pierson P., (2001), Introduction : Investigating the welfare state at the century's end, Pierson P., The new politics of the welfare state, Oxford University Press

Pieters D. (1999) (ed.), Changing work patterns and social security, Kluwer Law International -Reports, Briefing papers

HM Treasury, (2011) Integrating the operation of income tax and National Insurance contributions: A call for evidence

ICAEW, Tax Faculty, (2015) Income Tax and NIC - four options: a hard choice, BRIEFING PAPER

Stuart A., Loutzenhiser G., (2007) Integrating Income Tax and National Insurance: An Interim Report, The Institute for Fiscal Studies, WP21

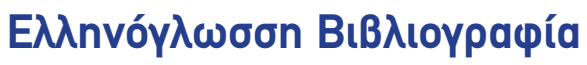

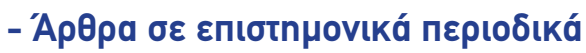

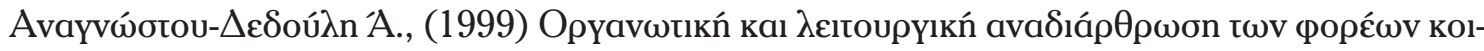

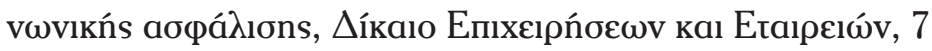

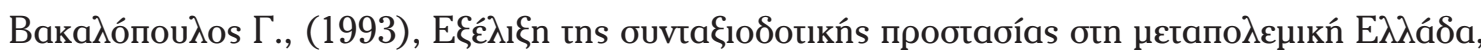
$\mathrm{E} \triangle \mathrm{KA}$, o.487-509

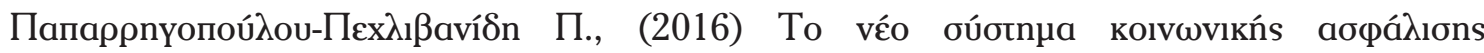
v.4387/2016, E $\triangle$ KA, זєúxos 2

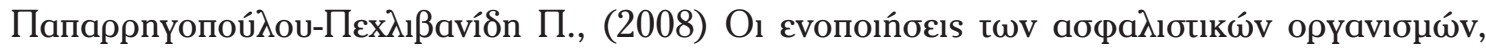
E $\triangle$ KA, т.3, б.177-191

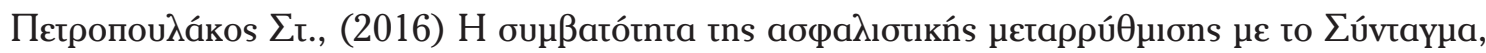
E $\Delta K A$, เعúxos 2

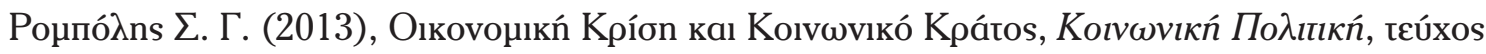




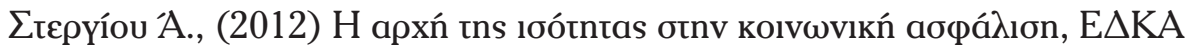

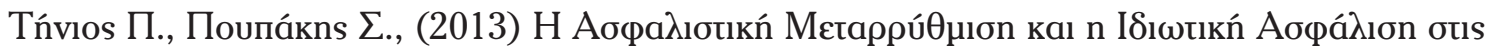

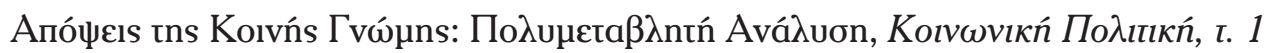

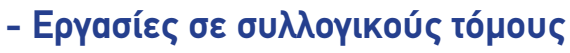

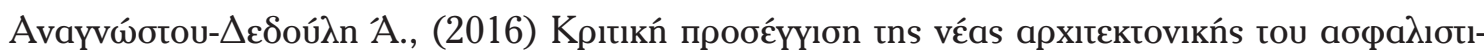

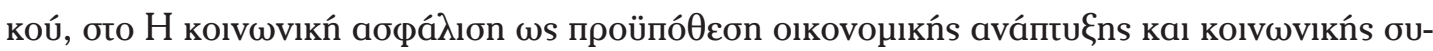
voxńs, EПКО $\Delta \mathrm{I}, \mathrm{Ek} \delta$. Папаそи́on

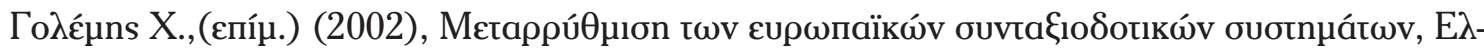

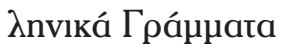

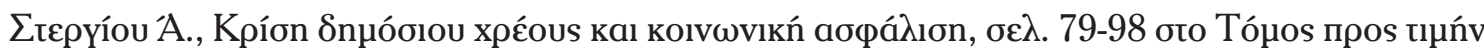

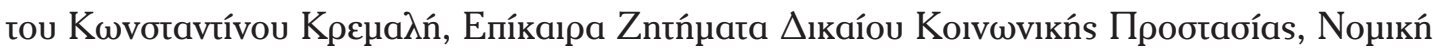
ВıßһıюӨ́́кn, 2016

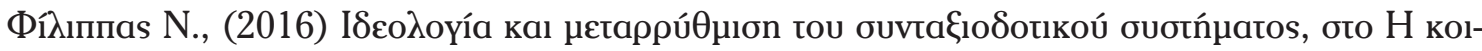

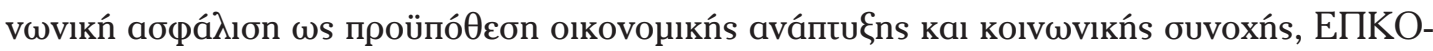
$\Delta \mathrm{I}$, Екס. Папаそ̆́non

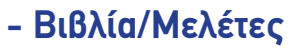

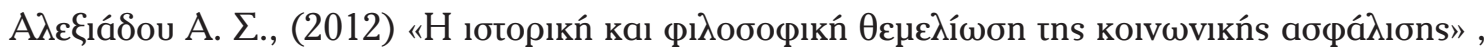

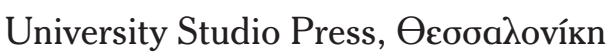

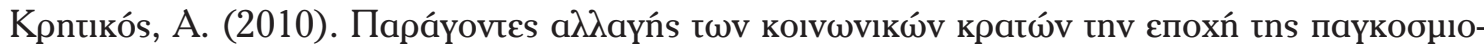

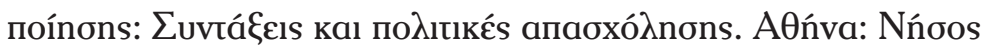

Папаррпүопои́

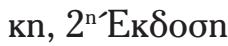

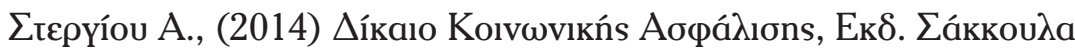

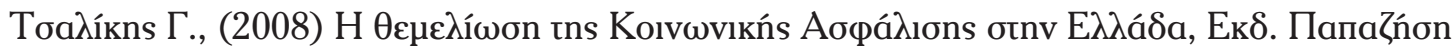

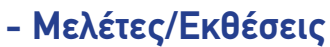

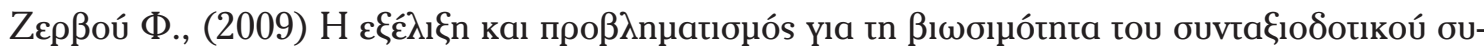

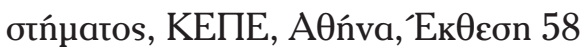

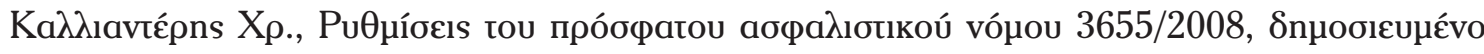
бто www.epkodi.gr

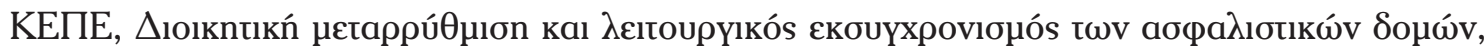
Ioúvios 2014

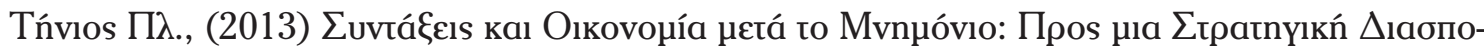

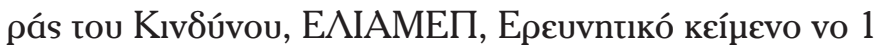

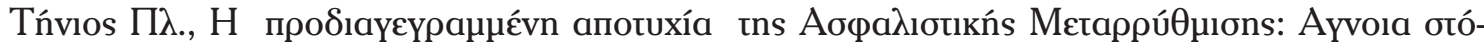

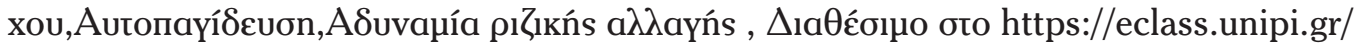

\section{- Порі́б}

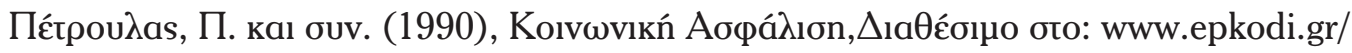




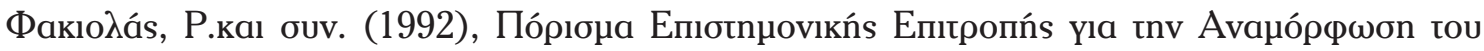

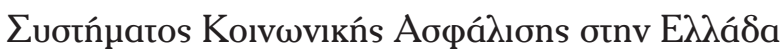

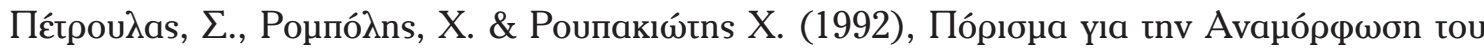

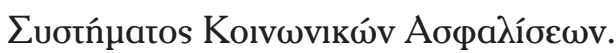

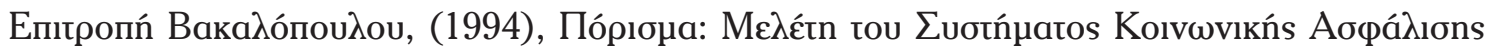

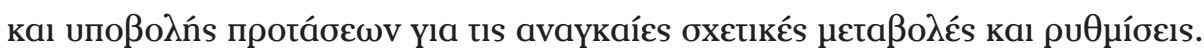

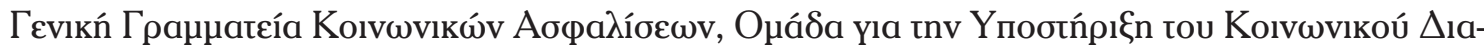

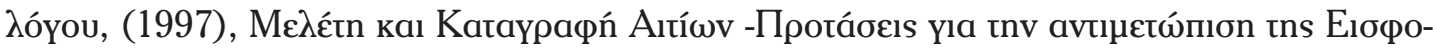

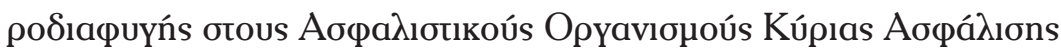

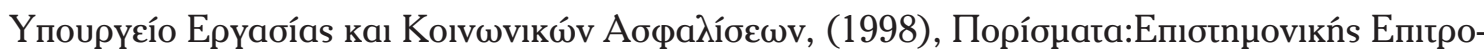

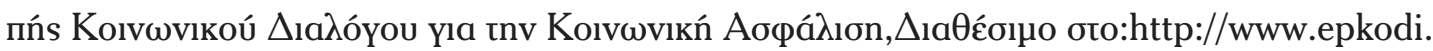
$\mathrm{gr} / \mathrm{site} /$

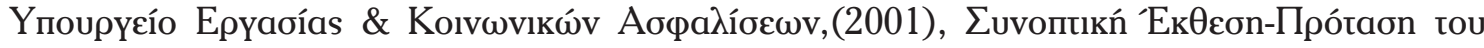

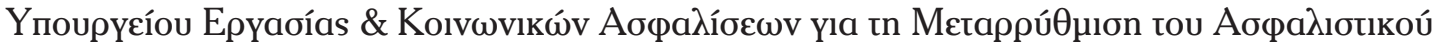

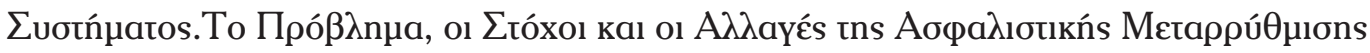

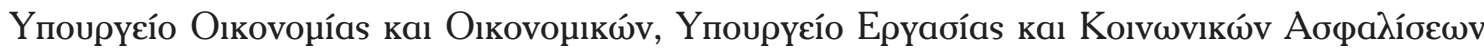

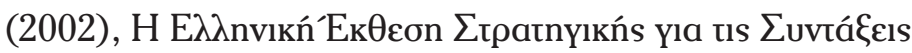

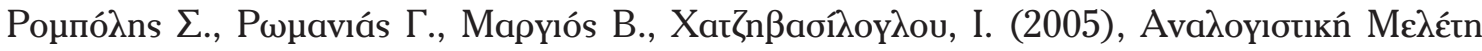

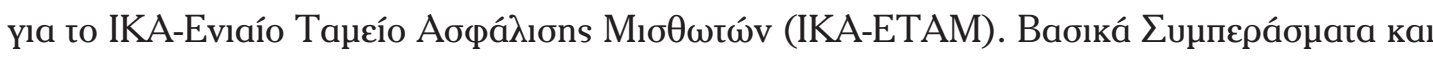

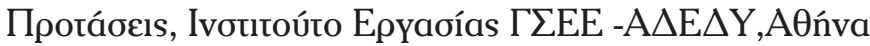

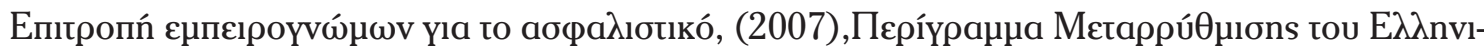

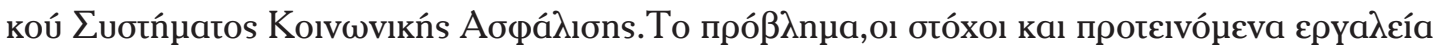

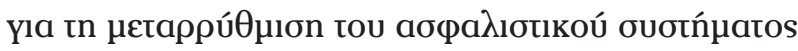

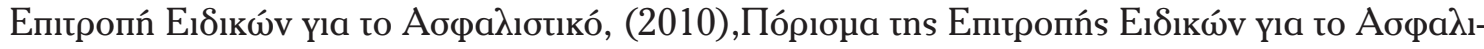

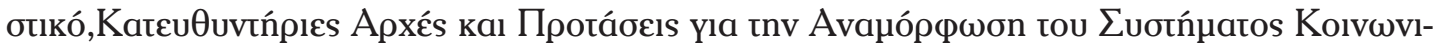

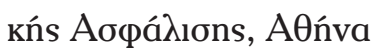

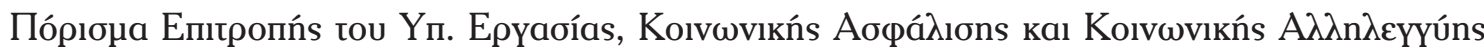

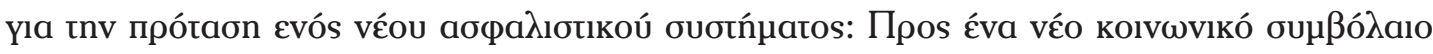

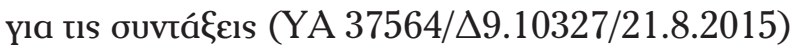

